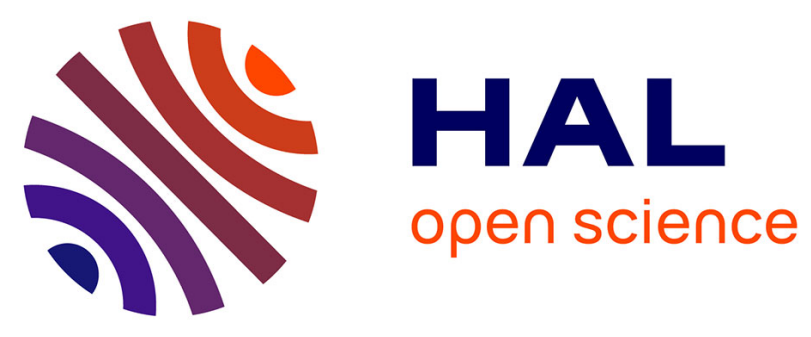

\title{
New reactive isoeugenol based phosphate flame retardant: toward green epoxy resins
}

\author{
Sylvie Pourchet, Rodolphe Sonnier, Marwa Abdelkader, Yves Gaillard, \\ Quentin Ruiz, Vincent Placet, Laurent Plasseraud, Gilles Boni
}

\section{To cite this version:}

Sylvie Pourchet, Rodolphe Sonnier, Marwa Abdelkader, Yves Gaillard, Quentin Ruiz, et al.. New reactive isoeugenol based phosphate flame retardant: toward green epoxy resins. ACS Sustainable Chemistry \& Engineering, 2019, 7 (16), pp.14074 - 14088. 10.1021/acssuschemeng.9b02629 . hal02370691

\section{HAL Id: hal-02370691 \\ https://hal.science/hal-02370691}

Submitted on 19 Nov 2019

HAL is a multi-disciplinary open access archive for the deposit and dissemination of scientific research documents, whether they are published or not. The documents may come from teaching and research institutions in France or abroad, or from public or private research centers.
L'archive ouverte pluridisciplinaire HAL, est destinée au dépôt et à la diffusion de documents scientifiques de niveau recherche, publiés ou non, émanant des établissements d'enseignement et de recherche français ou étrangers, des laboratoires publics ou privés. 


\section{A new reactive iso-eugenol based phosphate flame retardant:}

\section{toward green epoxy resins}

Sylvie Pourchet ${ }^{a *}$, Rodolphe Sonnier $^{b *}$, Marwa Ben-Abdelkader ${ }^{a}$, Yves Gaillard ${ }^{c}$, Quentin Ruiz $^{a}$, Vincent Placet ${ }^{c}$, Laurent Plasseraud $^{a}$, Gilles Boni $^{a *}$.

Authors address:

${ }^{\text {a } U n i v e r s i t e ́ ~ d e ~ B o u r g o g n e ~ F r a n c h e-C o m t e ́, ~ I C M U B ~ I n s t i t u t e, ~ U M R ~} 6302$ CNRS-UB, F-21000 DIJON, France.

${ }^{\mathrm{b}}$ IMT Mines ALÈS, Centre des Matériaux des mines d'Alès - Pôle Matériaux Polymères Avancés, 6 avenue de Clavières, 30319 ALÈS cedex, France.

c Université de Bourgogne Franche-Comté, FEMTO-ST Institute, UMR 6174 CNRS-UFCENSMM-UTBM, Department of Applied Mechanics, F-25000 BESANCON, France.

e-mail addresses of the corresponding authors :

Sylvie POURCHET sylvie.pourchet@u-bourgogne.fr

Rodolphe SONNIER rodolphe.sonnier@mines-ales.fr

Gilles BONI gilles.boni@u-bourgogne.fr

Keywords: iso-eugenol, phosphate flame retardant, bio-based resins, epoxy thermosets, high performance.

\section{ABSTRACT:}

A bio-based reactive phosphate flame retardant derived from iso-eugenol was synthesized and fully characterized $\left({ }^{1} \mathrm{H},{ }^{13} \mathrm{C},{ }^{31} \mathrm{P}\right.$ NMR, FTIR, MS) with the aim of improving flame retardancy 
behavior of bio-based epoxy thermosets. This new green flame retardant, diepoxy-iso-eugenol phenylphosphate (DEpiEPP) was then copolymerized either with conventional diglycidylether of bisphenol A resin (DGEBA) or with a totally bio-based glycidylether epoxy iso-eugenol (GEEpiE) resin using a bio-based camphoric anhydride (CA) as hardener. Resulting thermosets with varying rates of flame retardant ( 1.0 to $4.3 \mathrm{w} \%$ phosphorus) were then characterized (FTIR, DSC, nanoindentation, 3-point bending test, TGA, PCFC, cone calorimeter). By this way, a new solution was proposed allowing (i) to increase the bio-based content of thermosets (ii) to improve the flame retardancy properties by a reactive way and (iii) to provide epoxy thermosets with high Tg, excellent mechanical properties and a curing temperature compatible with the use of vegetable fibers. For instance, with a weight content of $2.0 \mathrm{w} \% \mathrm{P}$, both GEEpiECA-DEpiEPP (95\% bio-based content) and partially bio-based DGEBA-CA-DEpiEPP (57\% bio-based content) epoxy thermosets possess high $\mathrm{Tg}$ (respectively 129 and $105^{\circ} \mathrm{C}$ ), bending elastic modulus and strength of respectively $4.08 \mathrm{GPa}$ and $90 \mathrm{MPa}$ and demonstrate good flameretardant properties due to char promotion showing high promise for application.

\section{INTRODUCTION}

Epoxy thermosets are widely applied and constitute a large part of the thermosetting materials due to their high performances. ${ }^{1}$ Their chemical backbone often contains aromatic rings providing good mechanical and thermal behaviors. They offer useful adhesion and mechanical properties exhibiting also interesting chemical, electrical and heat resistances. Thus, these materials are also widely used in cutting-edge technological fields, such as aeronautics, automotive, electronic components and sports. However, most of the commonly used epoxy thermosetting polymers are petroleum-based. Furthermore, it is noteworthy that $90 \%$ of epoxy cross-linked polymers are synthesized from DGEBA (diglycidylether of bisphenol A). This resin is produced from BPA (bisphenol A) reactant, ${ }^{2}$ an endocrine disruptor and nephrotoxic 
compound that has received much attention due to its negative health effects ${ }^{3}$. Thus, in the view of decreasing the environmental impact, saving petroleum resources and replacing toxic BPA for the synthesis of epoxy, bio-based thermosets are widely studied. During the last decades many research works have therefore been dedicated to the specific domain of bio-based epoxy thermosets pointing out the potential of rosin, ${ }^{4}$ cardanol, ${ }^{5}$ iso-eugenol,,${ }^{6,7}$ eugenol, ${ }^{8-12}$, vegetable oil, ${ }^{13}$ modified lignin,,${ }^{14-16}$ vanillin,${ }^{17-19}$ terpene derivatives,${ }^{20}$ daidzein, ${ }^{21} \ldots$ to replace DGEBA epoxy monomer. Among the most promising feedstocks to replace BPA, building blocks derived from lignin, have been particularly pointed out. ${ }^{22-28}$ Indeed, with the objective of future industrial developments, accessibility and availability of the raw components are crucial parameters and have to be considered. Thus, lignin which is produced in large quantities (about 50 million tons of lignin per year are produced worldwide by the pulp and paper industry) constitutes the most abundant natural resource able to provide components containing rigid aromatic rings precursors of high performances thermosets ${ }^{29}$. Within this framework, Barta et $\mathrm{al}^{30}$ recently reviewed new platform chemicals arising from lignin.

In parallel, different studies also underlined the importance of substituting conventional toxic polyamine hardeners by anhydrides curing agents, potentially bio-based and containing rigid ring leading to a reinforcement of the thermosets mechanical properties. ${ }^{6,19,20,31,32}$

However, epoxy polymers are known to be highly flammable and to release a large amount of toxic smoke during their combustion. ${ }^{33}$ Thus, different approaches more mindful of health and of the environment were recently studied to improve the flame retardancy of epoxy thermosets in order to fulfill the flammability requirements for epoxy thermosets applications. The conventional approach is to add flame retardants (FRs) to epoxy thermosets. Most of these FRs contain phosphorus rather than halogen due to their toxic effect. Phosphorus FR act as char promoter in condensed phase and/or as flame inhibitor in gas phase. ${ }^{34}$ They can be phosphine oxide, phosphinate, phosphonate or phosphate and it is generally considered that their modes- 
of-action strongly depend on their oxidation level. ${ }^{35,36}$ Especially phosphate and phosphonate are rather effective in condensed phase by promoting charring of polymers.

Among these additives, DOPO and its derivatives have been extensively studied. ${ }^{37,38}$ Recently most of the studies were dedicated to the synthesis of new bio-based phosphorus-containing FRs. Howell and $\mathrm{Sun}^{39}$ have reported the beneficial effect of different bio-based FRs (molecules and oligomers) synthesized from tartaric acid and used as additive in a DGEBA matrix. Recently Wang et al. ${ }^{5}$ also used a cardanol-based phosphate as bio-based FR (Phosphaneanthrene groups-containing TrisCardanol Phosphate PTCP). The resulting thermosets (DGEBA-PTPC-aromatic diamine) showed that the FR addition accelerated the thermal degradation process and improved the char yield.

Nevertheless, the addition of non-reactive organophosphorus FRs of low molecular weight presents several drawbacks in connection with their potential volatility, causing their partial loss from the polymer by migration to the surface during the processing or ageing or in the early stages of combustion. Moreover, they can also act as plasticizers, leading to a decrease of the thermoset mechanical properties and/or also give rise to the formation of a segregated microphase. ${ }^{40}$ Furthermore, in the case of DOPO addition, an unintended consumption of epoxy group was reported, leading to a lower network density and a subsequent decrease of the thermoset Tg. ${ }^{41,42}$

Thus, the route which uses reactive organophosphorus FRs monomer is preferred in order to maximize the fire retardancy and to reduce the evolution of toxic species. Wang et al. ${ }^{43-45}$ have prepared epoxy resins containing phosphorus groups and some other groups (piperidine, imidazole, benzimidazole) to combine char promotion, radical quenching and fuel dilution effects. Phosphorus ionic liquids were also incorporated into epoxy network to impart flame retardancy. ${ }^{46,47}$ To increase the biobased content of materials, bioresources were also functionalized with phosphorus groups to be incorporated as reactive flame retardants. Various 
phosphorus groups were grafted to biomolecules derived from carbohydrates ${ }^{48}$, lipids ${ }^{49}$, terpenes $^{49}$, phenols $\mathrm{s}^{50-53}$ and so on. Biophenols are especially interesting due to the presence of aromatic rings. Ecochard et al. ${ }^{54}$ have shown that phosphorylated eugenol was more suitable than cardanol to improve the flame retardancy of epoxy resins, due to the aliphatic chains of cardanol limiting the charring. Within this framework, Wang and co-authors ${ }^{13}$ have synthesized two phosphorus-containing dicarboxylic acids FRs used as hardeners with epoxidized soybean oil with the aim of obtaining Pressure-Sensitive Adhesives having low Tg. The curing reaction was carried out at $180^{\circ} \mathrm{C}$ and authors reported a lower reactivity of the phosphorus-containing hardeners. Ma and coauthors ${ }^{48}$ have also reported the benefit in using a reactive phosphoruscontaining diepoxy FR synthesized from itaconic acid (EADI). This diepoxy FR was then copolymerized with DGEBA using MHHPA as hardener. Both these studies highlight the enhanced fire retardancy properties of the resulting thermosets induced by a charring effect, and this behavior depends on the environment of the phosphorus compound (aliphatic/aromatic/ester bonds).

It is noteworthy that the lower reactivity of both these phosphorus containing derivatives needs more severe curing conditions with higher curing temperature $\left(\mathrm{T}>180^{\circ} \mathrm{C}\right)$ making these matrices no longer compatible with the use of vegetable fibers.

Furthermore, some of the solutions currently proposed consist in using intrinsic fire retardancy properties of partially bio-based epoxy thermosets. Wan and al. ${ }^{10,55}$ demonstrated that high performance flame retardancy epoxy thermosets were obtained using an eugenol derivative epoxy resin with an aromatic polyamine. $\mathrm{Li}$ and co-authors ${ }^{56}$ also showed enhanced flame retardancy when silicon bridged difunctional epoxy monomers derived of eugenol were also cured with an aromatic polyamine (diamino diphenyl sulfone DDS). The high curing temperatures are incompatible with the use of vegetable fibers $\left(2 \mathrm{~h}\right.$ at $150^{\circ} \mathrm{C}$ and then $2 \mathrm{~h}$ at $\left.190^{\circ} \mathrm{C}\right)$. 
Thus, with the aim of developing fully bio-based composites containing vegetable fibers, our research team recently described a bio-based epoxy thermoset made of glycidylether epoxy isoeugenol (GEEpiE) resin cured with camphoric anhydride $(\mathrm{CA})$ at $150^{\circ} \mathrm{C}$. This totally bio-based material well fits with the mechanical properties required for structural composite applications using vegetable fibers as highlighted by their high instantaneous modulus of about $4.8 \mathrm{GPa}$ and curing temperatures. ${ }^{6}$ In our ongoing studies on the bio-based epoxy thermosets for high performance composite applications, we herein report the two steps synthesis of a reactive biobased phosphate flame retardant derived from iso-eugenol. Phenyldichlorophosphate first reacts with bio-based iso-eugenol according to a Williamson reaction. The second step consists of an oxidation of the alcene function by Oxone ${ }^{\circledR}$ as previously reported ${ }^{6}$ leading to the formation of the diepoxy-iso-eugenol phenylphosphate (DEpiEPP). The chemical structure of DEpiEPP was confirmed by ${ }^{1} \mathrm{H}, \mathrm{NMR},{ }^{13} \mathrm{C}$ NMR, ${ }^{31} \mathrm{P}$ NMR, FTIR and mass spectrometry (MS). Then the copolymerization of DEpiEPP either with conventional diglycidylether of bisphenol A resin (DGEBA) or with the totally bio-based glycidylether epoxy iso-eugenol (GEEpiE) using the bio-based camphoric anhydride (CA) as hardener was monitored by differential scanning calorimetry DSC and confirmed by FTIR. Finally, thermal (DSC) flame retardant (TGA, PCFC, cone calorimeter) and mechanical (nanoindentation, 3-point bending test) properties of the resulting thermosets containing varying rates of flame retardant ( 1 to $4.3 \mathrm{w} \%$ phosphorus) were investigated.

\section{EXPERIMENTAL SECTION}

Materials. Triethylamine (TEA, $\geq 99 \%$ purity, Sigma-Aldrich) and toluene (analytical grade, Carlo Erba) were purified by distillation. Dichloromethane (DCM, analytical grade, Carlo Erba) and acetone (analytical grade, Carlo Erba) were purchased and used as received. Phenyldichlorophosphate (PPDC, $\geq 95 \%$ purity, Sigma-Aldrich), sodium hydrogen carbonate 
$\left(\mathrm{NaHCO}_{3}, \geq 95 \%\right.$ purity, Sigma-Aldrich), tetrabutylammonium hydrogen sulfate $\left(\mathrm{Bu}_{4} \mathrm{NHSO}_{4}\right.$, $\geq 97 \%$ purity, Fluka) and Oxone ${ }^{\circledR}$ (Sigma-Aldrich) were purchased and used as supplied. Diepoxy synthon derived from iso-eugenol (GEEpiE) was prepared from biobased iso-eugenol according to a previously published procedure. ${ }^{7}$ Diglycidyl ether of bisphenol A (DGEBA, Sigma-Aldrich), isophorone diamine (IPDA, $\geq 99 \%$, Sigma-Aldrich), camphoric anhydride (CA, 98\% purity, Alfa Aesar) and 1,2-Dimethylimidazole (DMID, 95\% purity, Sigma-Aldrich) were purchased and used without any further purification. Phthalic anhydride (PA), diphenic anhydride (DPA) were prepared according to published procedures. ${ }^{8,57}$ Molecular representations of reagents used in the resin manufacturing process are presented in scheme 1.<smiles>CCCCCCCCC(C)(C)c1ccc(OCC2CO2)cc1</smiles><smiles>COc1cc(C2OC2C)ccc1OP(=O)(Oc1ccccc1)Oc1ccc(C2OC2C)cc1OC</smiles><smiles>COc1cc(C2OC2C)ccc1OCC1CO1</smiles>

\section{DEpiEPP}<smiles>CC1(C)CC(N)CC(C)(CN)C1</smiles>

IPDA

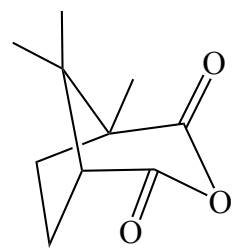

CA<smiles>O=C1OC(=O)c2ccccc21</smiles>

PA<smiles>O=c1oc(=O)c2ccccc2c2ccccc12</smiles>

DPA<smiles>Cc1nccn1C</smiles>

DMID 
Scheme 1. Molecular representations of reagents used. Epoxy monomers: diglycidylether of bisphenol A (DGEBA), glycidylether of phenoxy iso-eugenol (GEEpiE). Flame retardants: diepoxyiso-eugenolphenylphosphate (DEpiEPP). Curing agents: isophorone diamine (IPDA), camphoric anhydride (CA), phthalic anhydride (PA) and diphenic anhydride (DPA). Catalyst: 1,2-dimethylimidazole (DMID).

\section{Synthesis of glycidylether epoxy of iso-eugenol (GEEpiE)}

GEEpiE was prepared according to published procedure ${ }^{7}$ as follows (Scheme 2(a)).

\section{Synthesis of Di(iso-eugenol)phenylphosphate (DiEPP)}

Toluene $(25 \mathrm{~mL})$, triethylamine $(3.24 \mathrm{~mL}, 23.26 \mathrm{mmol})$ and iso-eugenol $(3.71 \mathrm{~mL}, 24.4 \mathrm{mmol})$ were introduced under argon atmosphere at $-10^{\circ} \mathrm{C}$ into a three-necked flask $(100 \mathrm{~mL})$ equipped with a digital thermometer, stirrer, refrigerant and dropping funnel. PPDC (1.76 mL, 11.74 mmol) was added dropwise for $15 \mathrm{~min}$. Then, the reaction mixture was slowly brought to room temperature and stirring continued overnight. The mixture was then solubilized in $10 \mathrm{~mL}$ of toluene and washed thrice with water and brine $(35 \mathrm{~mL})$. Organic phase was dried on anhydrous $\mathrm{MgSO}_{4}$. The toluene was driven off under reduced pressure to get a yellow viscous liquid. DiEPP was obtained with $74 \%$ yield.

IR (ATR, cm $\left.{ }^{-1}\right): 3019$ (aromatic C-H), $1655(\mathrm{C}=\mathrm{C}), 1589$ (aromatic $\left.\mathrm{C}=\mathrm{C}\right), 1299(\mathrm{P}=\mathrm{O}), 1030$ (P-O-C).

${ }^{1} \mathrm{H}-\mathrm{NMR}\left(500 \mathrm{MHz}, \mathrm{CDCl}_{3}\right): \delta \mathrm{ppm} 1.79\left(\mathrm{~m}, \mathrm{H}_{1}\right), 3.66\left(\mathrm{~m}, \mathrm{H}_{7}\right), 6.09$ and $6.25\left(\mathrm{~m}, \mathrm{H}_{2}\right.$ and $\left.\mathrm{H}_{3}\right)$, 6.77 and $7.12\left(\mathrm{~m}, \mathrm{H}_{4-6}, \mathrm{H}_{8-10}\right)$.

${ }^{13} \mathrm{C}-\mathrm{NMR}\left(125 \mathrm{MHz}, \mathrm{CDCl}_{3}\right): \delta$ ppm $18.5\left(\mathrm{~d}, \mathrm{C}_{1}\right), 55.8\left(\mathrm{~d}, \mathrm{C}_{10}\right), 109.9\left(\mathrm{~s}, \mathrm{C}_{9}\right), 118.3\left(\mathrm{~d}, \mathrm{C}_{6}\right)$; $120.4\left(\mathrm{~d}, \mathrm{C}_{12}\right), 121.3\left(\mathrm{~d}, \mathrm{C}_{2}\right), 125.2\left(\mathrm{~s}, \mathrm{C}_{14}\right), 126.1\left(\mathrm{~s}, \mathrm{C}_{5}\right), 129.5\left(\mathrm{~s}, \mathrm{C}_{13}\right), 130.3\left(\mathrm{~s}, \mathrm{C}_{3}\right), 138.7(\mathrm{~d}$, $\left.\mathrm{C}_{8}\right), 150.6\left(\mathrm{~d}, \mathrm{C}_{11}\right), 150.9\left(\mathrm{~d}, \mathrm{C}_{7}\right.$ and $\left.\mathrm{C}_{11}\right)$. 
${ }^{31} \mathrm{P}-\mathrm{NMR}\left(202 \mathrm{MHz}, \mathrm{CDCl}_{3}\right), \delta \mathrm{ppm}-16.7(\mathrm{~s}, \mathrm{P})$.

\section{Synthesis of Diepoxy iso-eugenol phenylphosphate (DEpiEPP)}

DiEPP (4.00 g, $8.58 \mathrm{mmol})$ solubilized in DCM $(50 \mathrm{~mL})$, water $(50 \mathrm{~mL})$, acetone $(6.6 \mathrm{~mL})$, $\mathrm{NaHCO}_{3}(3.71 \mathrm{~g}, 44.16 \mathrm{mmol})$ and $\mathrm{Bu}_{4} \mathrm{NHSO}_{4}(0.15 \mathrm{~g}, 0.44 \mathrm{mmol})$ were introduced into a binecked flask $(100 \mathrm{~mL})$ equipped with a digital thermometer, stirrer, refrigerant and dropping funnel. A solution of $O x o n e ®(8.11 \mathrm{~g}, 26.38 \mathrm{mmol})$ in water $(50 \mathrm{~mL})$ was added dropwise at $0^{\circ} \mathrm{C}$ for $30 \mathrm{~min}$ to the biphasic mixture vigorously stirred. Then, the reaction mixture was slowly brought to room temperature and stirring continued overnight.

The organic phase was washed thrice with saturated $\mathrm{NaCl}$ water $(50 \mathrm{~mL})$ and dried on anhydrous $\mathrm{MgSO}_{4}$. DCM was driven off under reduced pressure to get a yellow-brown very viscous liquid. DEpiEPP was obtained with $52 \%$ yield.

IR (ATR, cm $\left.{ }^{-1}\right): 3068$ (aromatic C-H), 1599 (aromatic C=C), $1299(\mathrm{P}=\mathrm{O}), 1025(\mathrm{P}-\mathrm{O}-\mathrm{C}), 904$ (epoxy ring), disappearance of $(\mathrm{C}=\mathrm{C})$ characteristic band at 1655 .

${ }^{1} \mathrm{H}-\mathrm{NMR}\left(500 \mathrm{MHz}, \mathrm{CDCl}_{3}\right): \delta \mathrm{ppm} 1.08\left(\mathrm{~d}, \mathrm{H}_{1}\right), 1.45\left(\mathrm{~d}, \mathrm{H}_{1}\right), 2.96\left(\mathrm{~m}, \mathrm{H}_{2}\right), 3.31\left(\mathrm{~m}, \mathrm{H}_{2}\right), 3.54$ $\left(\mathrm{d}, \mathrm{H}_{3}\right), 3.74\left(\mathrm{~s}, \mathrm{H}_{7}\right), 6.82$ and $7.30\left(\mathrm{~m}, \mathrm{H}_{4-6}, \mathrm{H}_{8-10}\right)$.

${ }^{13} \mathrm{C}-\mathrm{NMR}\left(125 \mathrm{MHz}, \mathrm{CDCl}_{3}\right): \delta \mathrm{ppm} 17.8\left(\mathrm{~s}, \mathrm{C}_{1}\right), 55.9\left(\mathrm{~s}, \mathrm{C}_{2}\right), 57.2\left(\mathrm{~s}, \mathrm{C}_{3}\right), 59.1\left(\mathrm{~s}, \mathrm{C}_{10}\right), 109.4$ (d, $\left.C_{9}\right), 118.0\left(\mathrm{~d}, \mathrm{C}_{6}\right), 120.3\left(\mathrm{~d}, \mathrm{C}_{12}\right), 121.3\left(\mathrm{~d}, \mathrm{C}_{14}\right), 125.2\left(\mathrm{~s}, \mathrm{C}_{5}\right), 129.5\left(\mathrm{~s}, \mathrm{C}_{13}\right), 136.1\left(\mathrm{~s}, \mathrm{C}_{4}\right)$, $139.5\left(\mathrm{~d}, \mathrm{C}_{8}\right), 150.8\left(\mathrm{~m}, \mathrm{C}_{7}\right.$ and $\left.\mathrm{C}_{11}\right)$.

${ }^{31} \mathrm{P}-\mathrm{NMR}\left(202 \mathrm{MHz}, \mathrm{CDCl}_{3}\right): \delta \mathrm{ppm}-16.8(\mathrm{~s}, \mathrm{P})$.

MS (m/z, ES+, [M+H']) calculated 498.468, found: 499.01. 
(a)

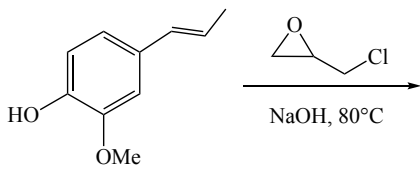

iEu

(b)

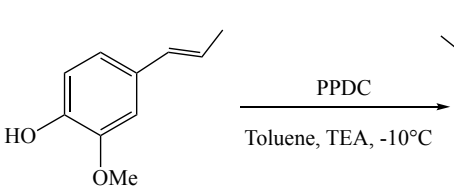

iEu

The stereochemistry is not specifed.$$
\text { socifed. }
$$

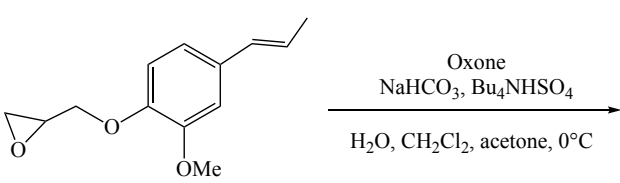

GEiE

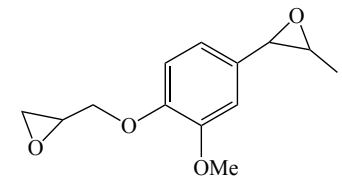

GEEpiE

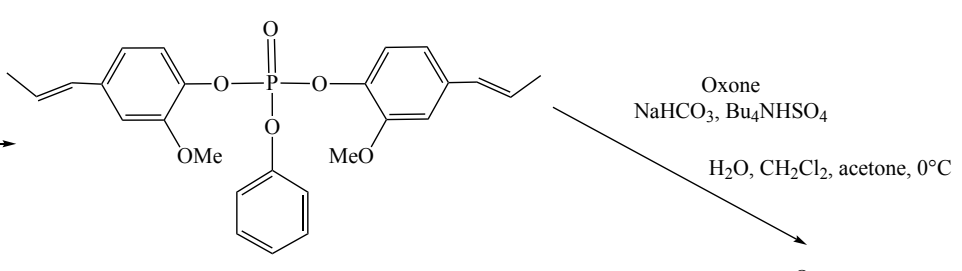

DiEPP

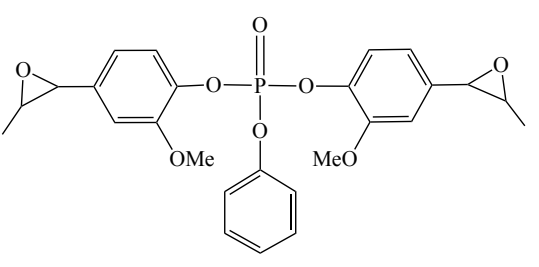

DEpiEPP

Scheme 2. Description of the diepoxy monomers synthesis.

NB: It is noteworthy that epichlorhydrin, used for the GEEpiE synthesis and DCM, used as solvent are highly toxic chemicals. They must be used referring to hazard caution information and replaced if possible.

\section{Thermosets curing protocol}

Polyepoxy polymers were obtained via thermal curing according to the protocol previously described. ${ }^{6}$ Diepoxy monomers containing different molar ratio of synthesized FR (DEpiEPP) were ground in a mortar at room temperature with anhydride hardeners (epoxide function/anhydride function molar ratio 1/0.6) until a homogeneous mixture was obtained. DMID catalyst was then added with a ratio of 0.025 eq. with respect to epoxide function. The mixture was cured in an oven at $150^{\circ} \mathrm{C}$ during $2 \mathrm{~h}$. The curing protocol for diepoxy monomer (DGEBA) and diamine hardener (IPDA) was the same, with an epoxide/amine molar ratio of $1 / 0.5$. 
For cone calorimeter samples, the reactants were first melted at $120^{\circ} \mathrm{C}$ until a homogeneous mixture was obtained and then DMID catalyst was added. Epoxy samples were obtained after curing in an oven at $120^{\circ} \mathrm{C}$ during $45 \mathrm{~min}$ and post-curing at $150^{\circ} \mathrm{C}$ for $1 \mathrm{~h}$.

Characterizations and instruments. IR spectra were recorded using an FTIR Bruker Alpha spectrophotometer fitted with an ATR module ALPHA-P equipped with a mono-reflexion diamond crystal in the $4000-375 \mathrm{~cm}^{-1}$ wavenumber range (32 scans at a spectral resolution of $\left.4 \mathrm{~cm}^{-1}\right)$.

${ }^{1} \mathrm{H},{ }^{13} \mathrm{C}$ and ${ }^{31} \mathrm{P}$ Nuclear magnetic resonance (NMR) spectra were obtained using a Bruker Avance III $500 \mathrm{MHz}$ spectrometer working at 500, 125 and $202 \mathrm{MHz}$, respectively, at room temperature and using $\mathrm{CDCl}_{3}$ as solvent. External references were trimethylsilane (TMS) for ${ }^{1} \mathrm{H}$ and ${ }^{13} \mathrm{C}$ NMR and phosphoric acid $\left(\mathrm{H}_{3} \mathrm{PO}_{4}\right)$ for ${ }^{31} \mathrm{P}$ NMR.

MS analysis was carried out in an HPLC Ultimate 3000 RSLC instrument from DIONEX coupled through an ElectroSpray Ionisation (ESI) interface to an ion-trap AmaZon SL mass spectrometer from Bruker for MS detection. Methanol was used as solvent.

Phosphorus elemental analyses were performed with inductively coupled plasma optical emission spectrometers ICP-OES (DUO) ICAP 7400. The cone calorimeter residue of the DEpiEu-CA series thermosets $(0.0 \%-2.0 \%-3.0 \% \mathrm{P})$ containing DEpiEPP was mineralized by microwave using $4 \mathrm{~mL}$ of $\mathrm{HNO}_{3}$ and water up to $10 \mathrm{~mL}$. Thus, the sample solution was nebulized and introduced into the center of the plasma.

DSC analyses were performed on a TA Instruments Discovery DSC under nitrogen flow (50 $\mathrm{mL} \mathrm{min}^{-1}$ ) with a sample masse of $10 \pm 3 \mathrm{mg}$. To study curing reaction, samples were heated from $0{ }^{\circ} \mathrm{C}$ to $230{ }^{\circ} \mathrm{C}$ at a heating rate of $5{ }^{\circ} \mathrm{C} \mathrm{min}{ }^{-1}$. The determination of glass transition temperatures ( $\mathrm{Tg}$ ) was carried out by heating the cured resin from $-20{ }^{\circ} \mathrm{C}$ to $240{ }^{\circ} \mathrm{C}$ at a heating rate of $20^{\circ} \mathrm{C} \mathrm{min}-1$ and using the TA Universal Analysis 2000 software. 
Thermogravimetic analyses were carried out using a TA Instruments Discovery TGA under either $\mathrm{N}_{2}$ atmosphere $\left(75 \mathrm{~mL} \mathrm{~min}^{-1}\right)$. Samples $(8-15 \mathrm{mg})$ were heated from room temperature to $800{ }^{\circ} \mathrm{C}$ at a heating rate of $20^{\circ} \mathrm{C} \mathrm{min}^{-1}$. Weight loss percentages were determined using the TA Universal Analysis 2000 software. $T_{5 \%}$ and $T_{\max }$ represent the temperature at which the material loses $5 \%$ of its initial mass and the temperature of the peak of mass loss rate respectively. Char content was measured at $600{ }^{\circ} \mathrm{C}$.

Flammability was assessed using a Pyrolysis-Combustion Flow Calorimeter (PCFC) from Fire Testing Technology (FTT UK). About $3 \mathrm{mg}$ was placed in the pyrolyzer, undergoing an increase of temperature from $20{ }^{\circ} \mathrm{C}$ to $750{ }^{\circ} \mathrm{C}$ at $1{ }^{\circ} \mathrm{C} \mathrm{s}^{-1}$ under a nitrogen flow. Decomposition gases were sent to a combustor heated at $900{ }^{\circ} \mathrm{C}$ under air flow $\left(\mathrm{N}_{2} / \mathrm{O}_{2}=80 / 20\right)$. At this temperature and with $20 \%$ of oxygen, combustion was considered to be complete. ${ }^{58}$ Heat release rate was determined by oxygen depletion according to Huggett principle ${ }^{59}(1 \mathrm{~kg}$ of consumed oxygen corresponds to $13.1 \mathrm{MJ}$ of heat released). pHRR is the maximal value of the heat release rate. The total heat released (THR) was obtained by integration of PCFC curves. Heat of combustion $(\Delta \mathrm{h})$ is the ratio between THR and weight loss fraction.

Thermosets fire behavior was also studied using a cone calorimeter (Fire Testing Technology) which is a powerful tool to investigate the fire behavior of polymers. A horizontal cylindrical sample sheet of $\phi 77 \times 3 \mathrm{~mm}$ was isolated by rock wool and placed at $6 \mathrm{~cm}$ below the conic heater because of the intumescent char formation observed. The samples were exposed to a 35 $\mathrm{kW} \mathrm{m}{ }^{-2}$ heat flux in well-ventilated conditions (air rate $24 \mathrm{~L} \mathrm{~s}^{-1}$ ) in the presence of a spark igniter to force the ignition. HRR was determined according to oxygen depletion (Huggett's relation) as in PCFC. This test was performed according to the ISO 5660 standard.

Nanoindentation experiments were performed using an ultra nanoindenter from Anton Paar. A Berkovich indenter was used. The area function was calibrated by indenting in a fused silica sample with a known Young's modulus and Poisson's ratio. Before carrying out the tests, the 
samples were polished with $\mathrm{SiC}$ paper, alumina particles until $0.03 \mathrm{~mm}$ and then colloidal silica. The instantaneous indentation modulus EI and hardness $\mathrm{H}$ at different indentation depths, the relaxed indentation modulus ER and finally the strain rate sensitivity $\mathrm{m}$ were determined from multicycle indentations, indentation at different constant strain rate $h / \mathrm{h}$ (where $\mathrm{h}$ is the indentation depth) and trapezoidal holding force tests with linear loading and unloading segments. The indentation protocols were the same as used previously. ${ }^{7}$

3-point bending tests were also performed using a universal testing machine MTS criterion 45 equipped with a $1 \mathrm{kN}$ full-range load sensor. Three samples of each batch were tested at a constant crosshead displacement rate of $1 \mathrm{~mm} / \mathrm{min}$. The total length of the specimen was approximately $50 \mathrm{~mm}$, and their width and thickness $3.5 \mathrm{~mm}$ and $2 \mathrm{~mm}$, respectively. The deflection was measured at mid-span, on the bottom face of the specimen, using a micrometer laser sensor. The support span was $40 \mathrm{~mm}$. The ultimate stress $\left(\sigma_{\max }\right)$, the 3 points bending modulus $(E)$ and the strain at failure $(\varepsilon)$ were determined from the load-deflection curves.

\section{RESULTS AND DISCUSSION}

\section{Synthesis of bio-based phosphorus-containing flame retardant}

To the best of our knowledge, the synthesis of diepoxy-iso-eugenol phenylphosphate (DEpiEPP) is unprecedented. This monomer combines both the iso-eugenol (iEu) bio-based synthon, which can be catalytically extracted from the lignin, ${ }^{60}$ and a phosphate group which can provide flame retardant properties.

DEpiEPP is prepared in two reaction steps as shown in scheme $2 b$. First the condensation of $\mathrm{iEu}$ and PPDC in toluene using TEA as acid acceptor leads to DiEPP. Epoxidation ${ }^{61}$ by Oxone ${ }^{\circledR}$ affords DEpiEPP in a $52 \%$ yield. DiEPP and DEpiEPP structures are confirmed by FTIR-ATR, ${ }^{1} \mathrm{H}$ NMR, ${ }^{31} \mathrm{P}$ NMR, ${ }^{13} \mathrm{C}$ NMR (see Figures $1-3$ ) and mass spectrometry. 
DiEPP and DEpiEPP formation is evidenced by the shift of the ${ }^{31} \mathrm{P}$ NMR signal from $4 \mathrm{ppm}$ in PPDC to -17 ppm (Figure 1). Not surprisingly the ${ }^{1} \mathrm{H}$ NMR spectrum of DiEPP (Figure 2a) combines the signals due to the iso-eugenol moiety and those of the phenoxy part. Assignments of the chemical shifts from ${ }^{1} \mathrm{H}$ NMR analysis shows the disappearance of the relative protons to $\mathrm{C}=\mathrm{C}$ linkage $(\delta=6.09-6.25 \mathrm{ppm})$ and the appearance of the oxirane ring protons $(\delta=2.96$ $3.54 \mathrm{ppm}$ ) in the DEpiEPP spectrum (Figure 2b).
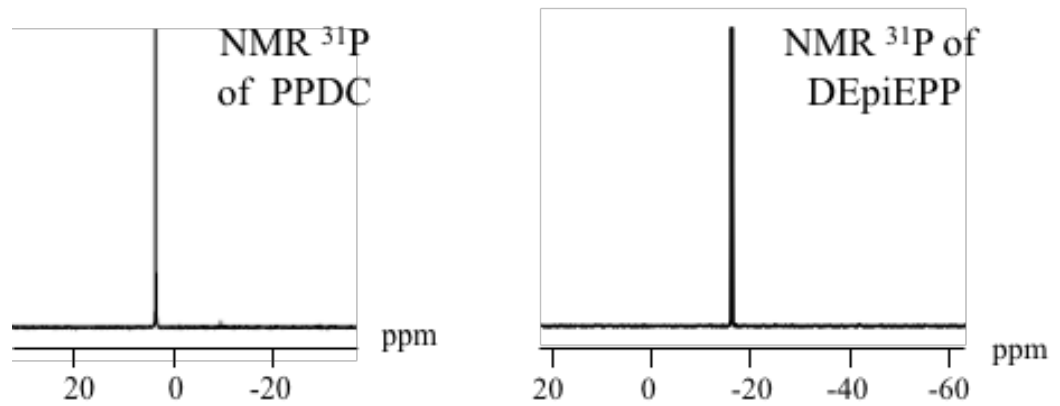

Figure 1. ${ }^{31} \mathrm{P}$ NMR spectra of PPDC (left) and DEpiEPP (right)

(a)

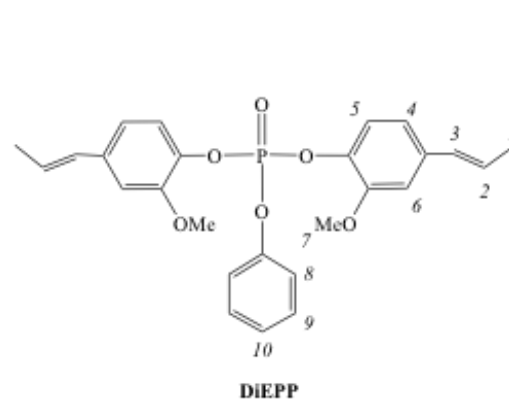

$\mathrm{H}_{7}$
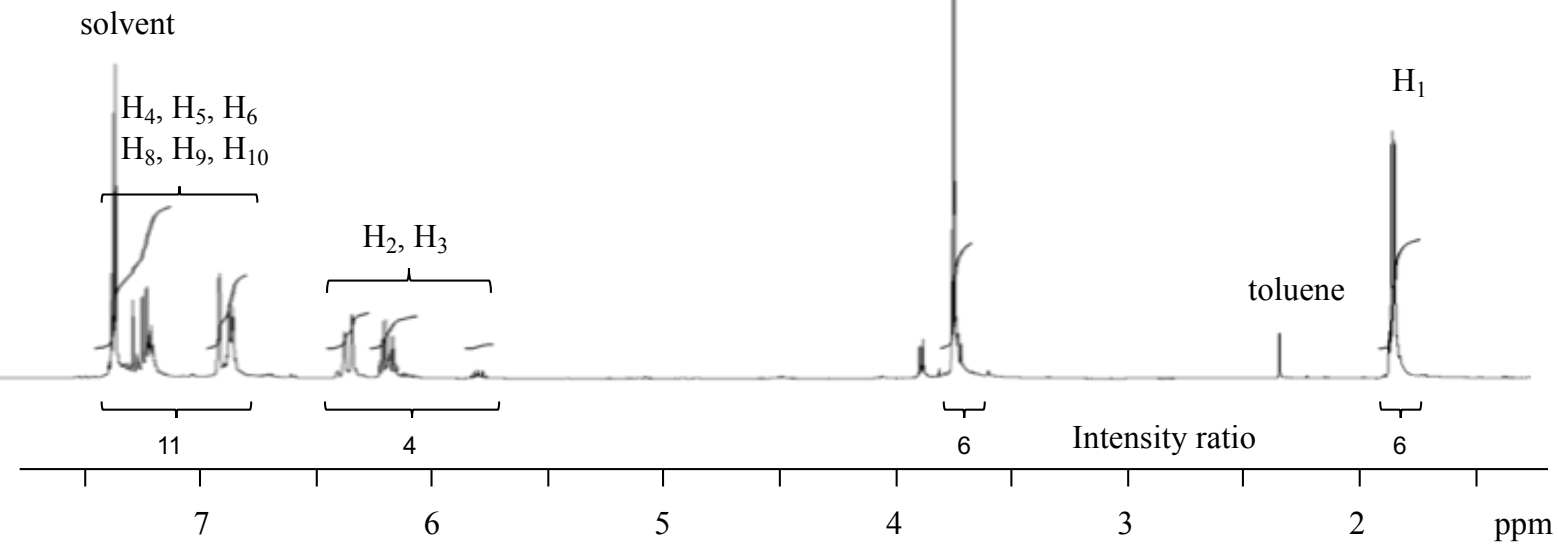


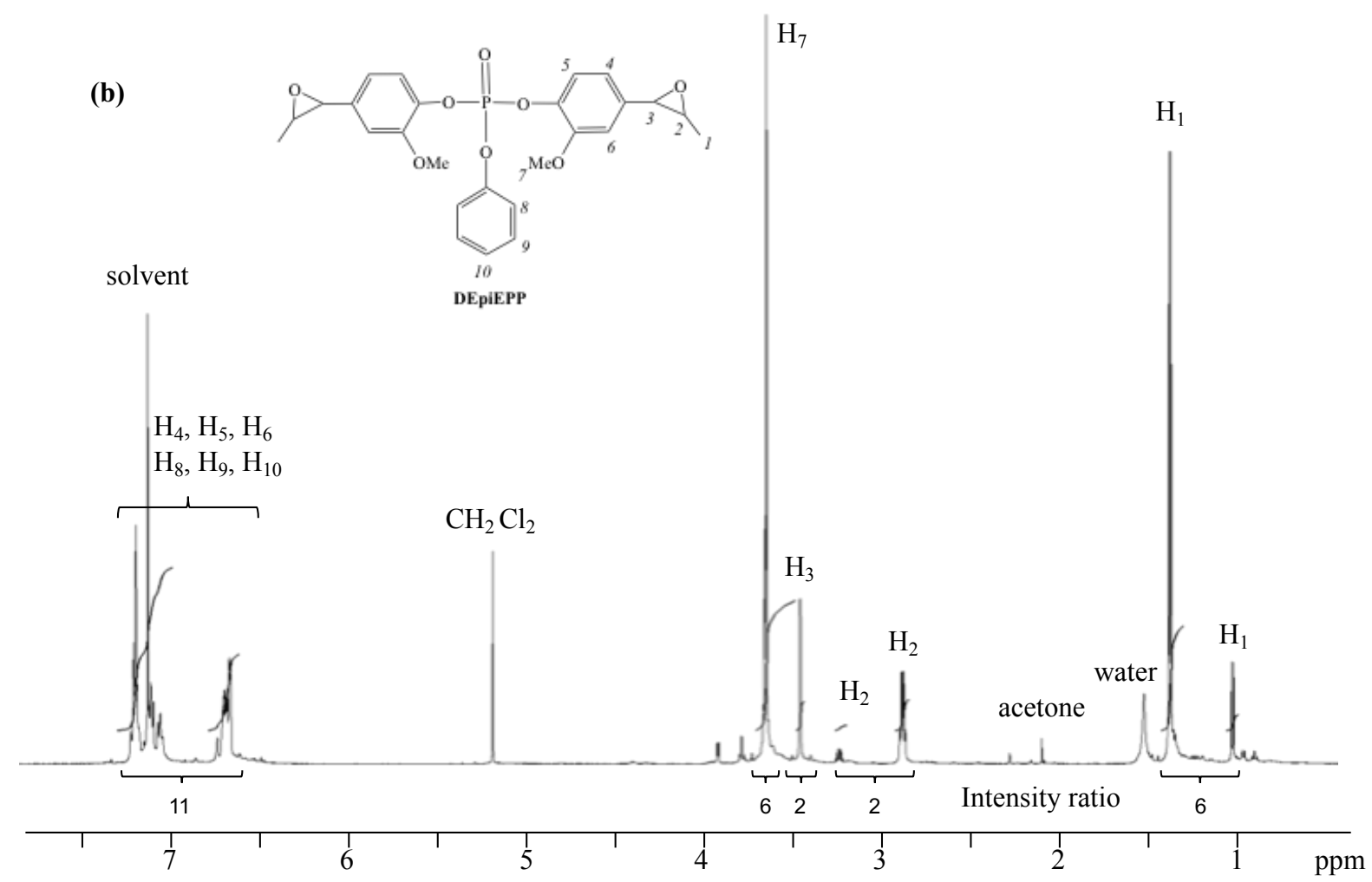

Figure 2. ${ }^{1} \mathrm{H}$ NMR spectra of: (a) DiEPP and (b) DEpiEPP

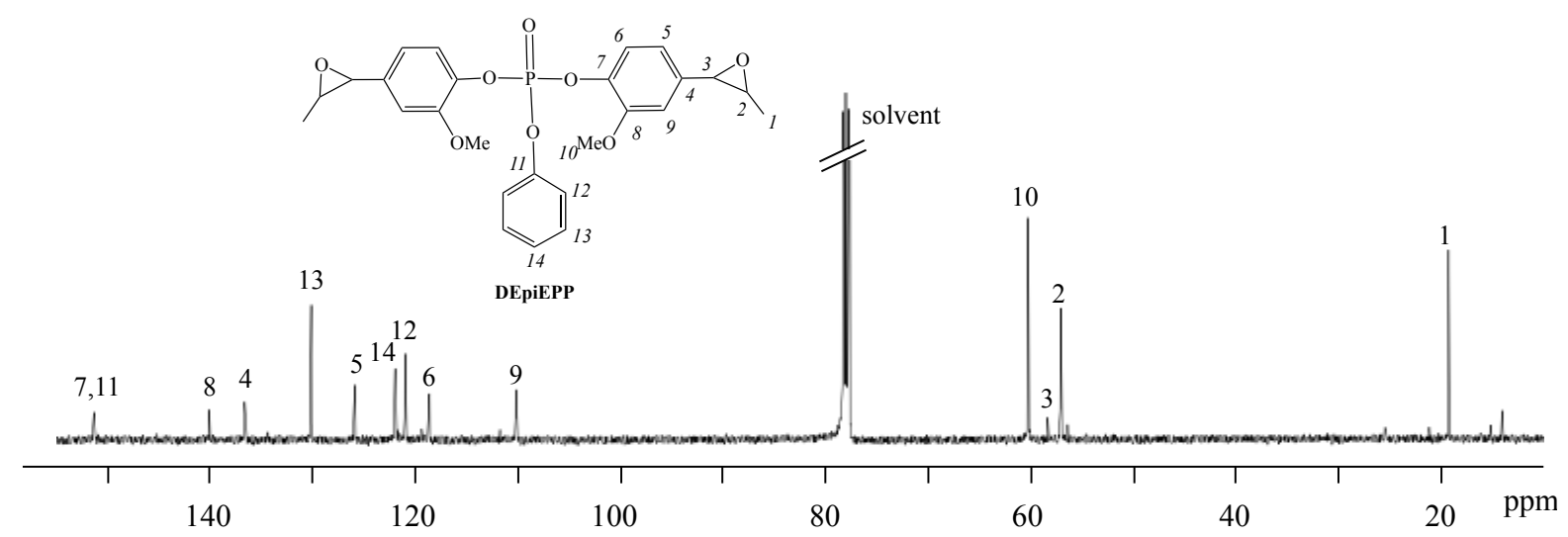

Figure 3. ${ }^{13} \mathrm{C}$ NMR spectra of DEpiEPP.

The FTIR spectra of DiEPP and DEpiEPP are in accordance with the DiEPP and DEpiEPP proposed structures. The P-O-C linkage is evidenced by a peak at $1030 \mathrm{~cm}^{-1}$ whereas the 
disappearance of the $\mathrm{C}=\mathrm{C}$ vinyl stretching band at $1655 \mathrm{~cm}^{-1}$ and the appearance of the oxirane ring at around $904 \mathrm{~cm}^{-1}$ confirm the DEpiEPP formation.

\section{Formulations studied}

With the aim of achieving $100 \%$ bio-based epoxy thermosets with flame retardancy properties, various formulations have been studied (Table 1).

\begin{tabular}{|c|c|c|c|}
\hline Thermosets & $\mathrm{P}^{\mathrm{a}}(\mathrm{w} \%)$ & $\begin{array}{l}\text { w\% epoxy / P-FR / } \\
\text { curing agent/DMID }\end{array}$ & $\begin{array}{l}\text { Bio-based } \\
\text { content }(\%)\end{array}$ \\
\hline \multirow{4}{*}{ DGEBA/ DEpiEPP / CA } & 0.0 & $60.4 / 0 / 38.8 / 0.9$ & 36 \\
\hline & 1.0 & $46.3 / 16.1 / 36.8 / 0.8$ & 47 \\
\hline & 2.0 & $32.3 / 32.1 / 34.8 / 0,8$ & 57 \\
\hline & 3.0 & $18.2 / 48.2 / 32.8 / 0.7$ & 68 \\
\hline \multirow{4}{*}{ GEEpiE / DEpiEPP / CA } & $\overline{0.0}$ & $51.4 / 0 / 47.6 / 1$ & 100 \\
\hline & 1.0 & $39.4 / 16.1 / 43.5 / 1$ & 96 \\
\hline & 2.0 & $27.5 / 32.1 / 39.5 / 0.9$ & 93 \\
\hline & 3.0 & $15.5 / 48.2 / 35.5 / 0.8$ & 89 \\
\hline DEpiEPP / CA & 4.3 & $0 / 69.1 / 30.3 / 0.7$ & 84 \\
\hline \multirow[t]{2}{*}{ GEEpiE / DEpiEPP / PA } & 0.0 & $56.4 / 0 / 42.5 / 1.1$ & 100 \\
\hline & 1.0 & $44 / 16.1 / 38.9 / 1$ & 96 \\
\hline \multirow[t]{2}{*}{ GEEpiE / DEpiEPP / DPA } & $\overline{0.0}$ & $46.3 / 0 / 52.8 / 0.9$ & 100 \\
\hline & 1.0 & $34.8 / 16.1 / 48.3 / 0.9$ & 97 \\
\hline
\end{tabular}

a. Phosphorus content (w\% P/thermoset)

Table 1 Weight compositions data of the thermosets.

The reactive P-FR has been copolymerized with two types of epoxy resins, the petroleum-based DGEBA and the bio-based GEEpiE in the presence of two types of hardeners, the petroleum- 
based IPDA and the bio-based anhydrides CA, PA and DPA. By this way epoxy materials ranging from petroleum-based $0 \%$ FR thermosets (DGEBA/IPDA) to totally bio-based FR thermosets (GEEpiE/DEpiEPP/CA) have been obtained.

DGEBA was selected as it is the most used epoxy monomer in industry thanks to its aromatic structure that brings rigidity to the networks and therefore mechanical properties are excellent. ${ }^{62,63}$ Anhydride curing agents (CA, PA, DPA) were chosen because they are bio-based and contain rigid ring leading to a reinforcement of the thermosets mechanical properties, whereas IPDA was selected as a model of polyamine hardener. ${ }^{13}$

The diepoxy monomer/anhydride hardener and diepoxy monomer/polyamine molar ratio were equal to $1 / 1.2$ and $2 / 1$ respectively, as previously reported. ${ }^{6,64}$

Thermosets with varying rates of P-FR, from 0.0 to $4.3 \mathrm{w} \%$ phosphorus, have been produced (the $4.3 \mathrm{w} \%$ phosphorus sample corresponds to pure DEpiEPP).

\section{Curing step}

Curing of epoxy resins with CA hardener has been investigated by DSC. Samples were heated from $0{ }^{\circ} \mathrm{C}$ to $230{ }^{\circ} \mathrm{C}$ at a heating rate of $5{ }^{\circ} \mathrm{C} \min ^{-1}$. DSC thermograms are depicted in Figure 4.

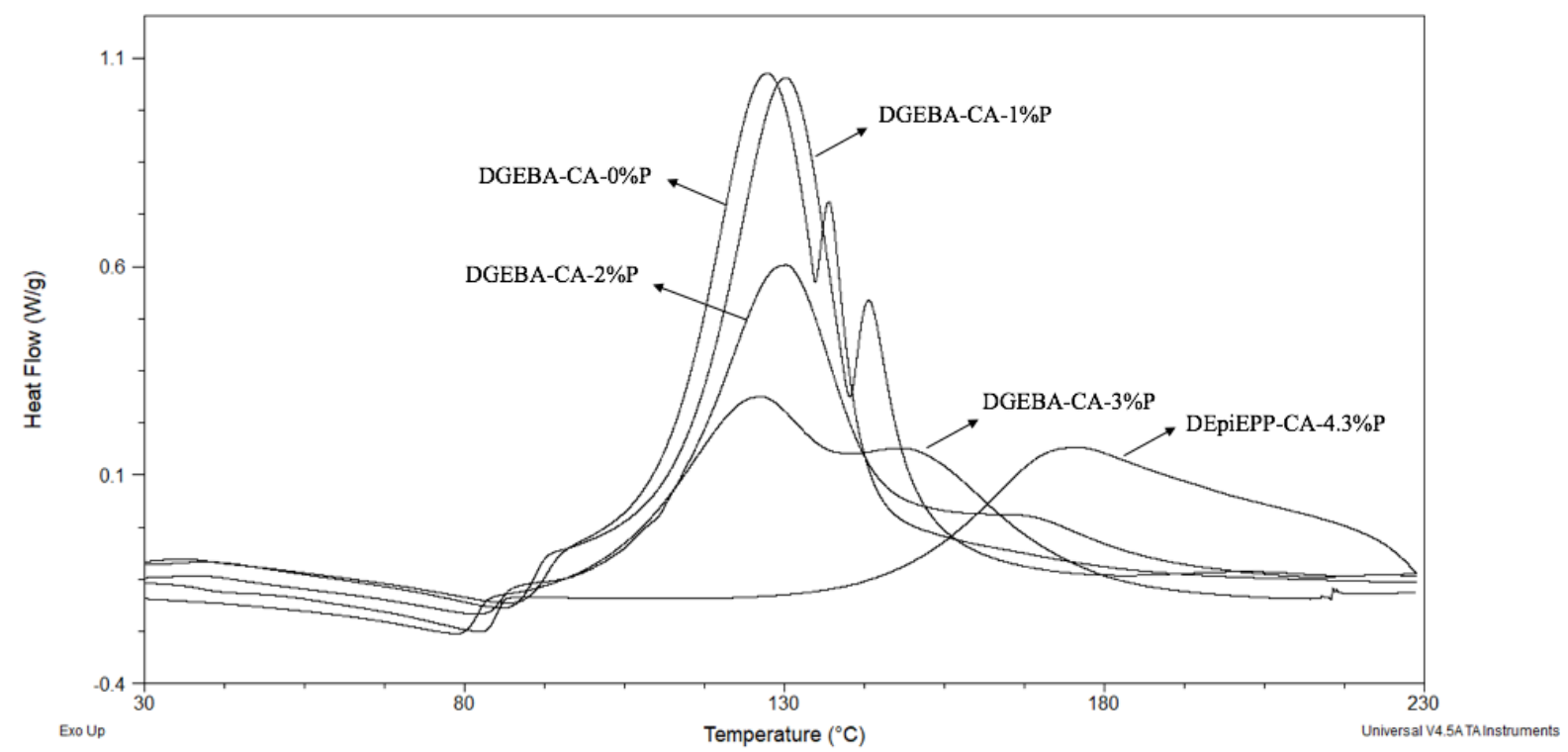




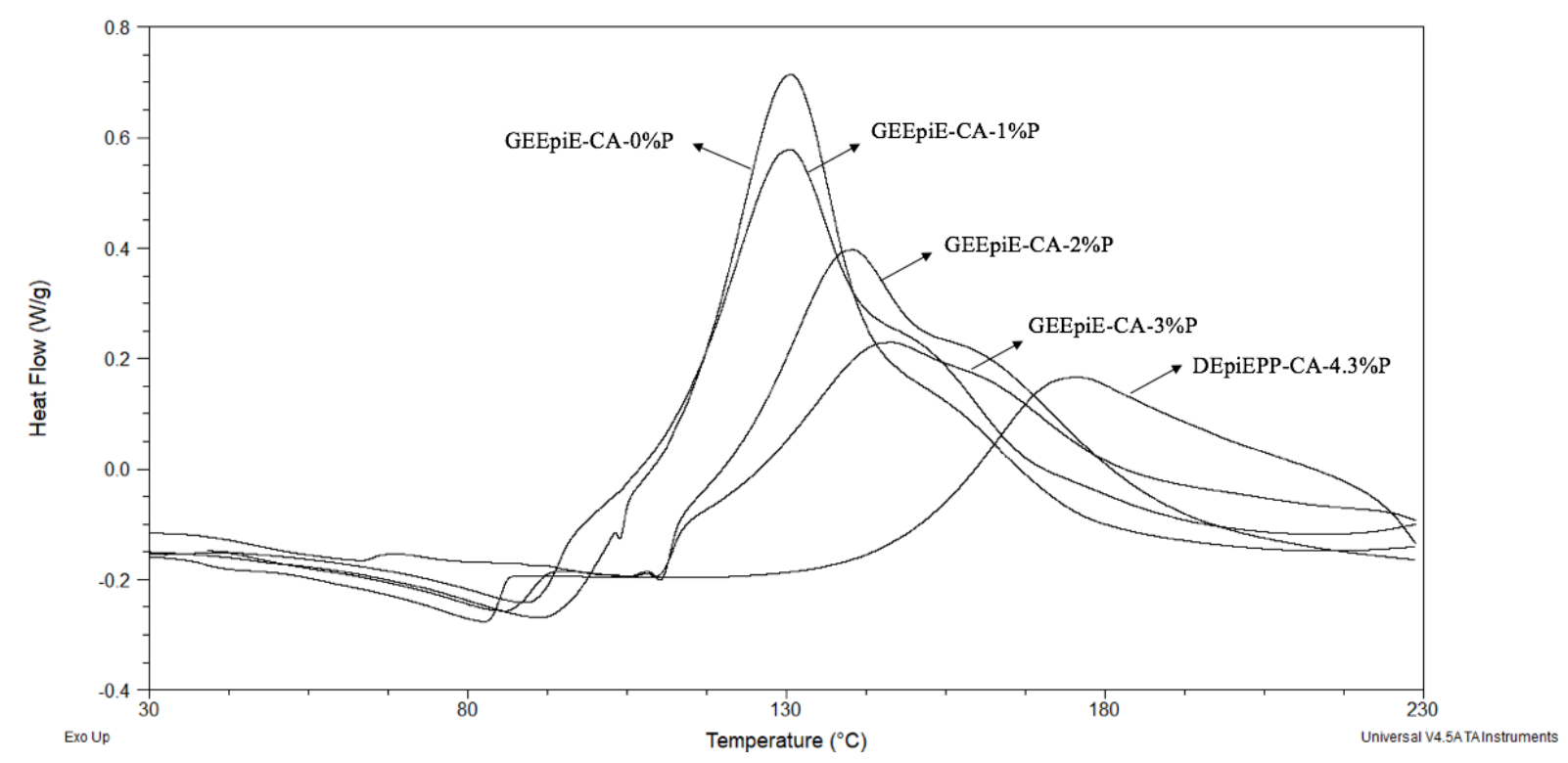

Figure 4. DSC curves of dynamic curing reaction (above) DGEBA/CA (below) GEEpiE/CA series thermosets with varying DEpiEPP contents $(0.0$ to $4.3 \% \mathrm{P})$.

\section{DSC}

Thermosets

$$
\begin{array}{llll}
\cline { 2 - 3 } & \text { Polymerization } & & \\
\mathrm{P}^{\mathrm{a}}\left({ }_{\mathrm{w}} \%\right) & \text { Peak } \mathrm{T}\left({ }^{\circ} \mathrm{C}\right) & \Delta \mathrm{H}(\mathrm{J} / \mathrm{g}) & \mathrm{Tg}^{\mathrm{b}}\left({ }^{\circ} \mathrm{C}\right) \\
& \text { Start-end } \mathrm{T}\left({ }^{\circ} \mathrm{C}\right) & &
\end{array}
$$

\begin{tabular}{llllll}
\hline DGEBA/DEpiEPP / IPDA & 0.0 & $/$ & $/$ & 155
\end{tabular}

\begin{tabular}{lccccc}
\hline & 0.0 & $90-160$ & 127 and 137 & 383 & 155 \\
\cline { 2 - 5 } DGEBA/ DEpiEPP / CA & 1.0 & $90-170$ & 130 and 143 & 371 & 137 \\
\cline { 2 - 5 } & 2.0 & $95-195$ & 130 & 289 & 105 \\
\cline { 2 - 5 } & 3.0 & $95-185$ & 126 and 150 & 261 & 89 \\
\hline & 0.0 & $95-180$ & 131 & 346 & 162 \\
\cline { 2 - 5 } GEEpiE / DEpiEPP / CA & 1.0 & $95-195$ & 130 & 349 & 136 \\
\cline { 2 - 6 } & 2.0 & $110-220$ & 140 & 312 & 129 \\
\cline { 2 - 6 } & 3.0 & $110-230$ & 145 & 230 & 97 \\
\hline DEpiEPP / CA & 4.3 & $150-230^{c}$ & 175 & 194 & 71 \\
\hline GEEpiE / DEpiEPP / PA & 0.0 & & & & 115 \\
\hline
\end{tabular}




\begin{tabular}{|c|c|c|c|c|c|}
\hline & 1.0 & $*$ & $*$ & $*$ & 84 \\
\hline \multirow{2}{*}{ GEEpiE / DEpiEPP / DPA } & 0.0 & & & & 123 \\
\hline & 1.0 & $*$ & $*$ & $*$ & 113 \\
\hline
\end{tabular}

a: Phosphorus content (w\% P/thermoset)

$\mathrm{b}$ : Glass temperature of thermosets cured in the oven

c: Beginning of the thermoset degradation à $230^{\circ} \mathrm{C}$.

Table 2: DSC data of the thermosets.

Thermograms exhibit an exothermic peak related to the cross-linking reaction. As highlighted in table 2, when increasing the P-FR content, the exothermic peak is broadened and shifted to higher temperatures and the curing enthalpies concomitantly decrease, whatever the epoxy resin used. These phenomena reveal a lower reactivity of oxirane groups of the P-FR, in accordance with observations reported by Wan et al.. ${ }^{55}$ Indeed, the polarizability of the epoxy group progressively decreases in the order DGEBA, GEEpiE and DEpiEPP. In DGEBA and GEEpiE, the epoxy reactivity of the glycidyl ether groups is enhanced due to the presence of adjacent oxygen (induction effect). In addition, steric hindrance could also explain this lower oxirane reactivity. To confirm the lower reactivity of oxirane groups in the P-FR, complementary curing tests have been carried out at higher temperature $\left(180^{\circ} \mathrm{C}\right)$ for DEpiEPP/CA $(4.3 \% \mathrm{P})$. The resulting thermoset exhibits a higher $\mathrm{Tg}$ of $84^{\circ} \mathrm{C}$ (instead of $71^{\circ} \mathrm{C}$ when curing temperature is $\left.150^{\circ} \mathrm{C}\right)$. However, as the $\mathrm{Tg}$ reflects both the crosslinking degree of the thermoset and its chemical structure, the P-FR chemical structure must also be considered.

With the aim of developing fully bio-based composites containing vegetable fibers, attention must be paid to the onset and exothermic peak temperatures in order to avoid the polymerization during the step of fiber impregnation and to prevent their damage. ${ }^{6}$ It is noteworthy that all formulations well fit these requirements while a homogeneous paste is obtained at about $90^{\circ} \mathrm{C}$ 
and the cross-linking reaction occurs below $160^{\circ} \mathrm{C}$. Both thermoset series are thus suitable for manufacturing bio-composite reinforced by vegetable fibers.

\section{Glass transition temperature of the cured epoxy resins (DSC)}

The DSC curves for the DGEBA/CA and GEEpiE/CA thermoset series are shown in Figure 5, and glass transition temperatures are reported in Table 2. It is noticeable that, for all the studied thermosets, no additional exothermal peak is observed in DSC after the curing schedule showing that the cross-linking reaction is ended. Moreover, as mentioned by Couture et al, ${ }^{20}$ the initiator (DMID) could act as a thermoset plasticizer, decreasing thus the network Tg. Thus, higher Tg could be expected by precisely optimizing the required initiator quantity.

Not surprisingly, the Tg values progressively decrease as the P-FR content increases: the initial high $\mathrm{Tg}$ of about $160^{\circ} \mathrm{C}$ (free P-FR thermosets) drops to $71{ }^{\circ} \mathrm{C}$ when the only P-FR (free DGEBA/GEEpiE) is cured. However, it is interesting to note that with a phosphorus weight content equal or lower than $2.0 \%$, high $\operatorname{Tg}\left(>100^{\circ} \mathrm{C}\right)$ are obtained with both GEEpiE-CADEpiEPP (95\% bio-based content) and partially bio-based DGEBA-CA-DEpiEPP (57\% biobased content) epoxy thermosets. Interestingly the fully bio-based thermoset GEEpiE-CADEpiEPP, exhibits Tg of respectively $136^{\circ} \mathrm{C}$ and $129^{\circ} \mathrm{C}$ with the phosphorus weight contents of 1.0 or $2.0 \%$.

As previously reported, phtalic and diphenic anhydrides were also found to be candidates as curing agents to obtain bio-based epoxy matrices for high performance composites. Thus, formulations of GEEpiE with both these anhydrides and with the green P-FR DEpiEPP were studied with a phosphorus weight content of $1.0 \%$ (see table 2). A Tg decrease of the same order $\left(10\right.$ to $\left.30^{\circ} \mathrm{C}\right)$ was again recorded when the epoxy resin was copolymerized with DEpiEPP, demonstrating that this effect remains the same whatever the hardener chemical structure. The Tg decrease has to be correlated with the lower reactivity highlighted by DSC recording during 
the curing step, inducing then a lower cross-linking density. Similar effects were also reported and attributed to steric hindrance due to phosphate groups in the studies of Wang and coauthors $^{13}$ or Ma and coauthors. ${ }^{48}$

Thereby, both GEEpiE-CA-DEpiEPP (95\% bio-based content) and partially bio-based DGEBA-CA-DEpiEPP (57\% bio-based content) epoxy thermosets with the phosphorus weight contents of $2.0 \%$ seem to be good candidates for composite application in connection with their high $\operatorname{Tg}$ (respectively 129 and $105^{\circ} \mathrm{C}$ ) compatible with further applications of the final material.

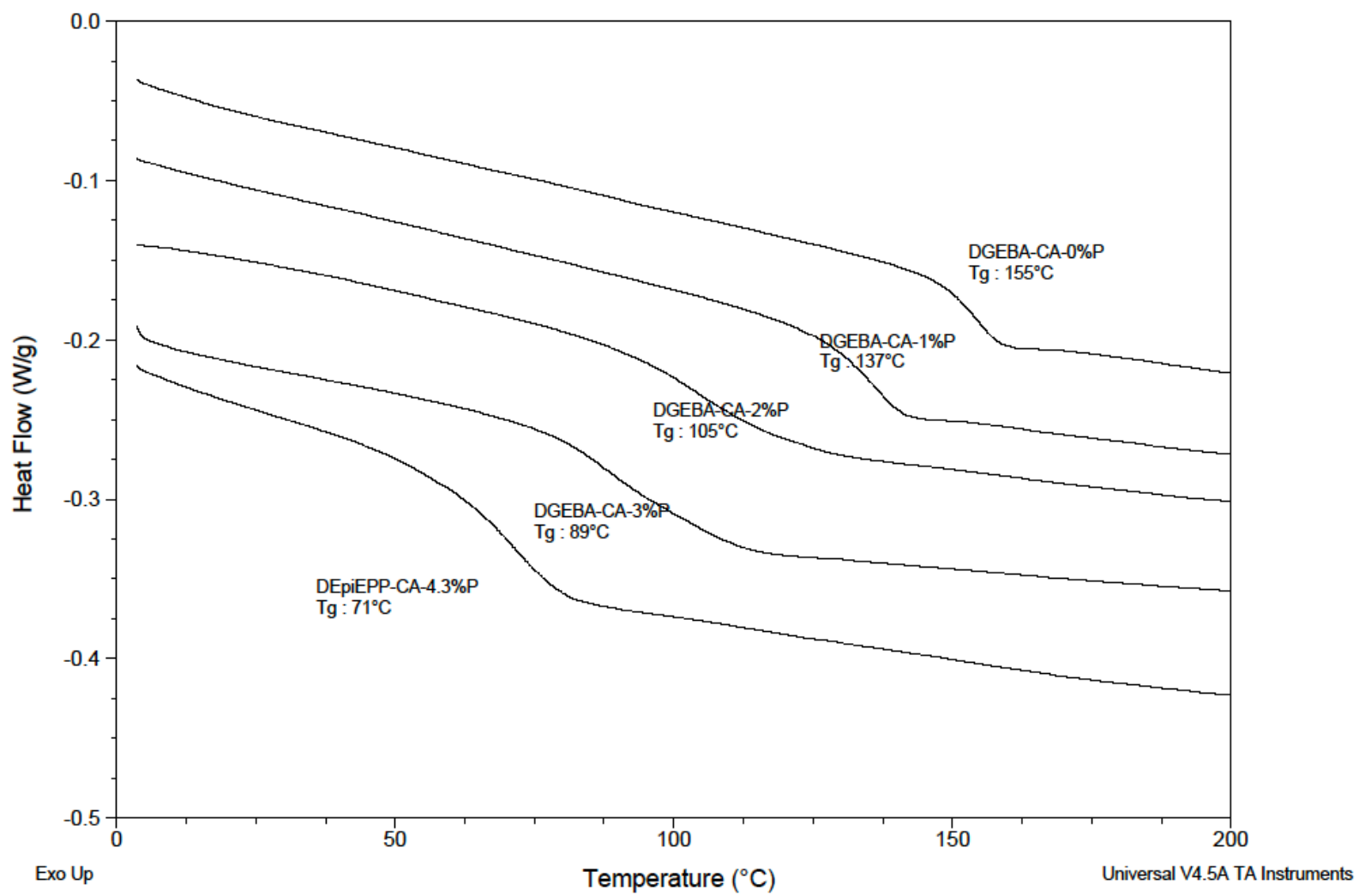




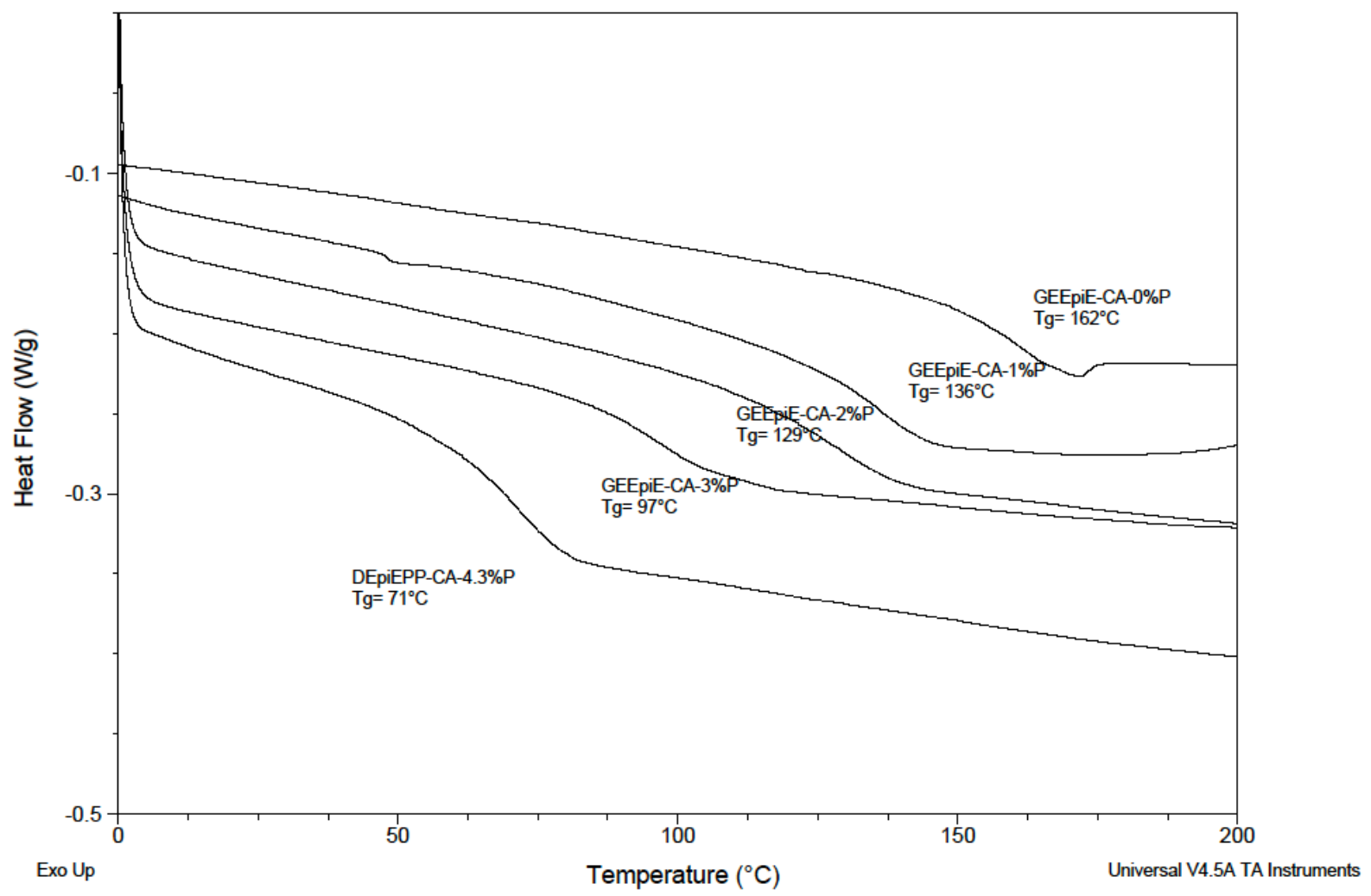

Figure 5. Determination of the glass transition by DSC (above) DGEBA/CA and (below) GEEpiE/CA thermoset series at different phosphorus content of DEpiEPP.

\section{Thermal degradation behaviour of the cured epoxy resins at microscale (TGA and PCFC)}

Anaerobic pyrolysis and complete combustion of flame retarded thermosets were characterized at microscale using TGA and PCFC (Table 3).

\begin{tabular}{|c|c|c|c|c|c|c|c|c|}
\hline \multirow[t]{2}{*}{ Formulation } & \multirow[t]{2}{*}{$\% \mathbf{P}$} & \multicolumn{3}{|c|}{ TGA } & \multicolumn{3}{|c|}{ PCFC } & \multirow{2}{*}{$\begin{array}{c}\Delta \mathrm{h} \\
(\mathrm{kJ} / \mathrm{g})\end{array}$} \\
\hline & & $\begin{array}{l}\mathbf{T}_{5 \%} \\
\left({ }^{\circ} \mathbf{C}\right)\end{array}$ & $\begin{array}{l}\text { Tmax } \\
\left({ }^{\circ} \mathrm{C}\right)\end{array}$ & $\begin{array}{l}\text { Residue } \\
(\mathbf{w} \%)\end{array}$ & $\begin{array}{l}\text { pHRR } \\
(W / g)\end{array}$ & $\begin{array}{l}\text { TpHR } \\
\text { R }\left({ }^{\circ} \mathrm{C}\right)\end{array}$ & $\begin{array}{c}\text { THR } \\
(\mathrm{kJ} / \mathrm{g})\end{array}$ & \\
\hline DGEBA / IPDA & 0.0 & 355 & 382 & 9.0 & 648 & 370 & 28.3 & 31.1 \\
\hline DGEBA / CA & 0.0 & 386 & 435 & 7.4 & 477 & 426 & 25.1 & 26.4 \\
\hline DGEBA / DEpiEPP / CA & 1.0 & 322 & 381 & 15.5 & 631 & 388 & 22.4 & 25.7 \\
\hline DGEBA / DEpiEPP / CA & 2.0 & 308 & 382 & 16.8 & 687 & 372 & 21.3 & 24.8 \\
\hline
\end{tabular}




\begin{tabular}{ccccccccc}
\hline DGEBA / DEpiEPP / CA & 3.0 & 296 & 370 & 17.9 & 501 & 361 & 20.8 & 25.1 \\
\hline GEEpiE / CA & 0.0 & 364 & 430 & 8.7 & 336 & 409 & 22.9 & 24.6 \\
\hline GEEpiE / DEpiEPP / CA & 1.0 & 309 & 380 & 14.7 & 367 & 375 & 21.1 & 23.4 \\
\hline GEEpiE / DEpiEPP / CA & 2.0 & 301 & 366 & 15.0 & 402 & 368 & 20.7 & 23.8 \\
\hline GEEpiE / DEpiEPP / CA & 3.0 & 293 & 357 & 18.3 & 363 & 361 & 20.2 & 24.6 \\
\hline DEpiEPP / CA & 4.3 & 274 & 312 & 19.6 & 181 & 367 & 17.6 & 22.9
\end{tabular}

Table 3 Data of the TGA and PCFC analyses of all the prepared thermosets.

Figure 6 and Figure 7 show the thermograms and HRR curves performed for DGEBA/CA and GEEpiE/CA thermoset series at different phosphorus contents. Both P-free thermosets exhibit close thermal stability and char ability ( $\mathrm{T}_{5 \%}$ is slightly lower for the latter). Note that their temperature at maximum mass loss rate is significantly higher than for DGEBA/IPDA thermoset.

For both thermoset series, it is noted that the thermal stability is lower than that of corresponding P-FR-free matrices and it depends clearly on the phosphorus content (Figure 8). Higher is the phosphorus content, lower are the onset temperature $\mathrm{T}_{5 \%}$ and temperature at peak of mass loss rate $\mathrm{T}_{\max }$ in TGA. TpHRR in PCFC follows the same tendency and is generally close to $\mathrm{T}_{\max }$. As an example, $\mathrm{T}_{5 \%}$ is reduced from $386{ }^{\circ} \mathrm{C}$ for the $0 \mathrm{w} \% \mathrm{P}$ (DGEBA/CA) thermoset to $322{ }^{\circ} \mathrm{C}$ for the $1.0 \mathrm{w} \% \mathrm{P}$ (DGEBA / DEpiEPP / CA) and to $296{ }^{\circ} \mathrm{C}$ for the $3 \mathrm{w} \%$ P (DGEBA / DEpiEPP / CA). Concerning the GEEpiE-based thermosets, $\mathrm{T}_{5 \%}$ is reduced from $364{ }^{\circ} \mathrm{C}$ for the $0.0 \mathrm{w} \% \mathrm{P}(\mathrm{GEEpiE} / \mathrm{CA})$ thermoset to $309^{\circ} \mathrm{C}$ for the $1.0 \% \mathrm{P}(\mathrm{GEEpiE} / \mathrm{DEpiEPP}$ / CA) and to $293{ }^{\circ} \mathrm{C}$ for the $3.0 \mathrm{w} \% \mathrm{P}$ (GEEpiE / DEpiEPP / CA) (and to $274{ }^{\circ} \mathrm{C}$ for $4.3 \mathrm{w} \%$ P). These lower degradation temperatures are partly due to the reduced crosslink density and mostly to the early stage of decomposition for phosphorus-containing groups. ${ }^{5,65}$ Indeed, phosphorus flame retardants decompose into phosphoric acids and dehydrate oxygen-rich 
polymers promoting their charring. Note that the decrease is similar for both series (DGEBA and GEEpiE series).

Peak of heat release rate is highly dependent on the network structure, i.e. on the chemical groups constituting the network. DGEBA/IPDA exhibits a higher pHRR $\left(648 \mathrm{~W} \mathrm{~g}^{-1}\right)$ than DGEBA/CA (477 $\mathrm{W} \mathrm{g}^{-1}$ ) and GEEpiE/CA (336 W/g). Interestingly the incorporation of phosphorus does not lead to a reduction of pHRR. On the contrary, for low phosphorus content, the pHRR not only is reached at lower temperature but it also increases significantly and becomes narrower. This evidences that the phosphorus monomer (DEpiEPP) induces a thermal destabilization of the network. At higher content, the decomposition occurs in several wellidentified peaks especially for GEEpiE/CA 3.0\% P and DEpiEPP/CA 4.3\% P. Therefore, the main pHRR decreases. There is no monotonous decrease in pHRR, as observed in other studies. THR of P-free thermosets is in the range $22.9-28.3 \mathrm{~kJ} \mathrm{~g}^{-1}$ depending on the network structure. Once again, GEEpiE/CA exhibits the lowest THR $\left(22.9 \mathrm{~kJ} \mathrm{~g}^{-1}\right)$ while DGEBA/CA shows intermediate value $\left(25.1 \mathrm{~kJ} \mathrm{~g} \mathrm{~g}^{-1}\right)$. The increase of phosphorus content leads to a slight and continuous reduction in THR to $20.8 \mathrm{~kJ} \mathrm{~g}^{-1}$ and $20.2 \mathrm{~kJ} \mathrm{~g}^{-1}$ for $3.0 \mathrm{w} \% \mathrm{P}$ (respectively DGEBA/CA and GEEpiE/CA). As explained below, this reduction is mainly due to an enhancement of char content rather than to a decrease in heat of combustion.

According to the char content, the DEpiEPP improves the charring of the matrix during thermal decomposition as expected. For DGEBA/CA and GEEpiE/CA thermoset series, the char content increases with the phosphorus content. It raises from $7.4 \mathrm{w} \%$ for the P-FR-free matrix to $15.5 \mathrm{w} \%$ with $1.0 \mathrm{w} \% \mathrm{P}$ and to $17.9 \mathrm{w} \%$ with $3.0 \mathrm{w} \% \mathrm{P}$ for DGEBA-based thermosets. Concerning the GEEpiE-based thermosets, the char content increases from $8.7 \mathrm{w} \%$ for the PFR-free matrix to $14.7 \mathrm{w} \%$ with $1.0 \mathrm{w} \% \mathrm{P}$ and to $18.3 \mathrm{w} \%$ with $3.0 \mathrm{w} \% \mathrm{P}$ (and up to $19.6 \mathrm{w} \%$ with $4.3 \mathrm{w} \% \mathrm{P}$ ). These results reveal that DEpiEPP seems to be a good flame retardant since it promotes a significant charring of both epoxy thermosets. 
Heat of complete combustion was calculated from THR and residue content data. For both series, heat of complete combustion seems to decrease marginally. Indeed, char traps a large amount of carbon and reduces the energy released by pyrolysis gases. It has already been shown that the atomic composition of char is close to $\mathrm{C}_{5} \mathrm{H}_{2}$ for a couple of polymers ${ }^{66}$ corresponding to an energy released by char oxidation higher than $30 \mathrm{~kJ} \mathrm{~g}^{-1}$ Nevertheless the heat stored in char containing phosphorus is generally lower. ${ }^{67}$
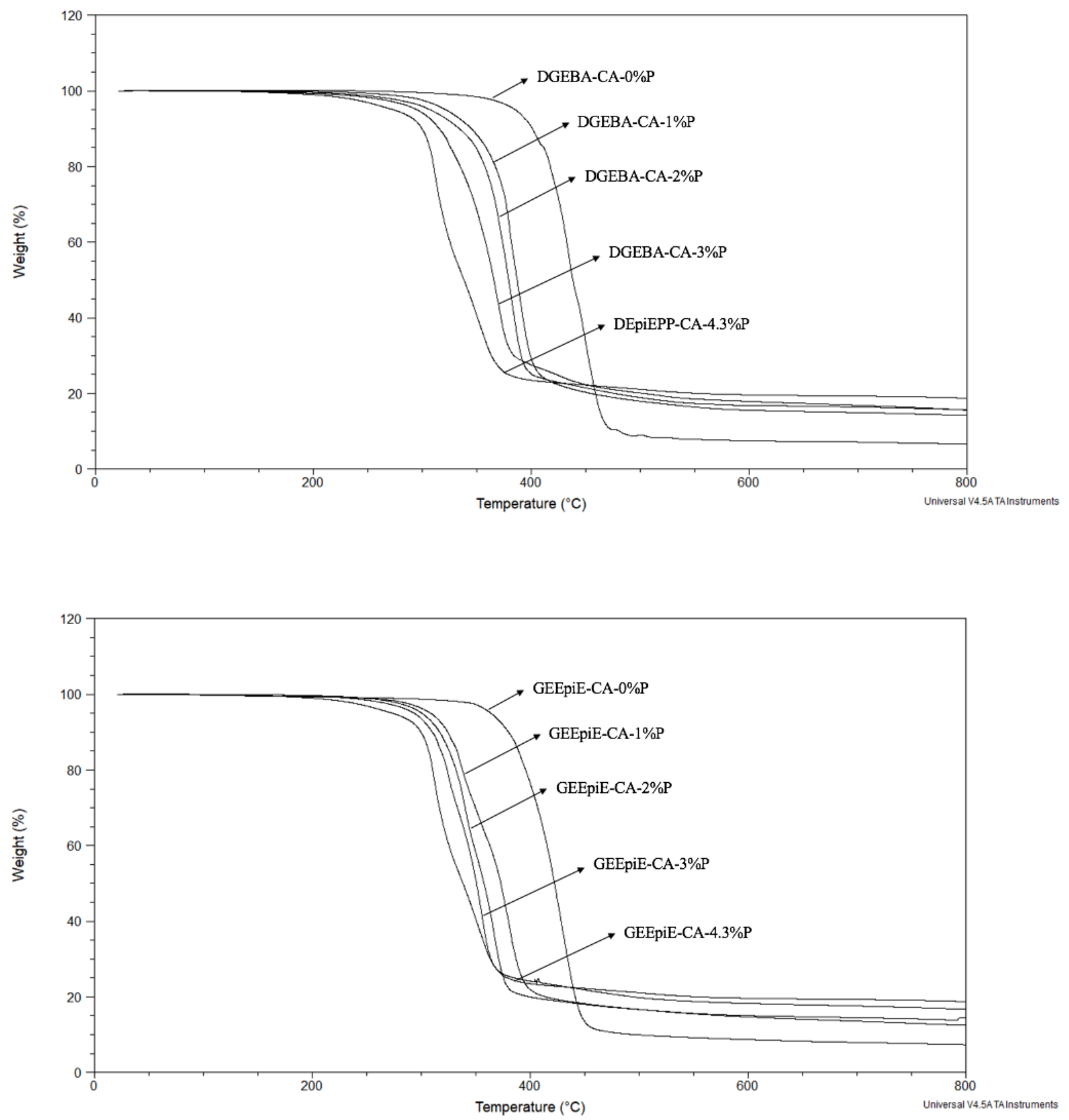

Figure 6. Thermograms of (above) DGEBA/CA and (below) GEEpiE/CA thermoset series at different phosphorus contents obtained by TGA at $20{ }^{\circ} \mathrm{C} \mathrm{min}^{-1}$ under nitrogen atmosphere. 

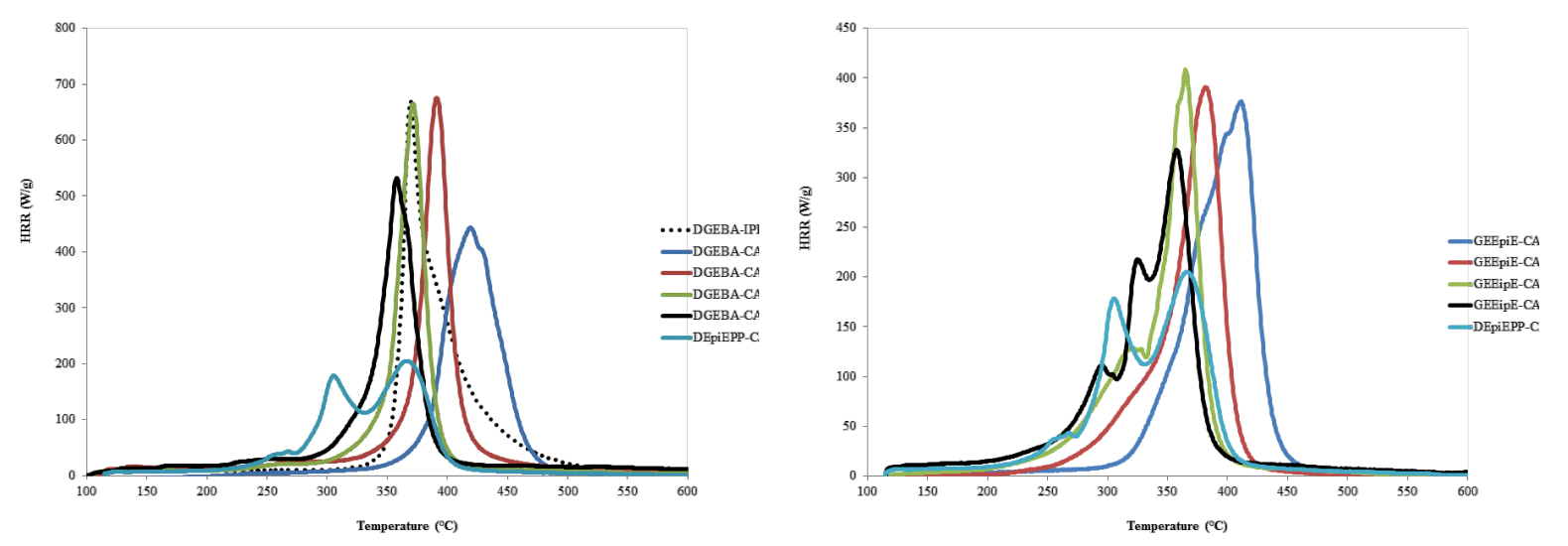

Figure 7. HRR curves of (left) DGEBA/IPDA and DGEBA/CA and (right) GEEpiE/CA thermoset series at different phosphorus contents obtained by PCFC in standard conditions.

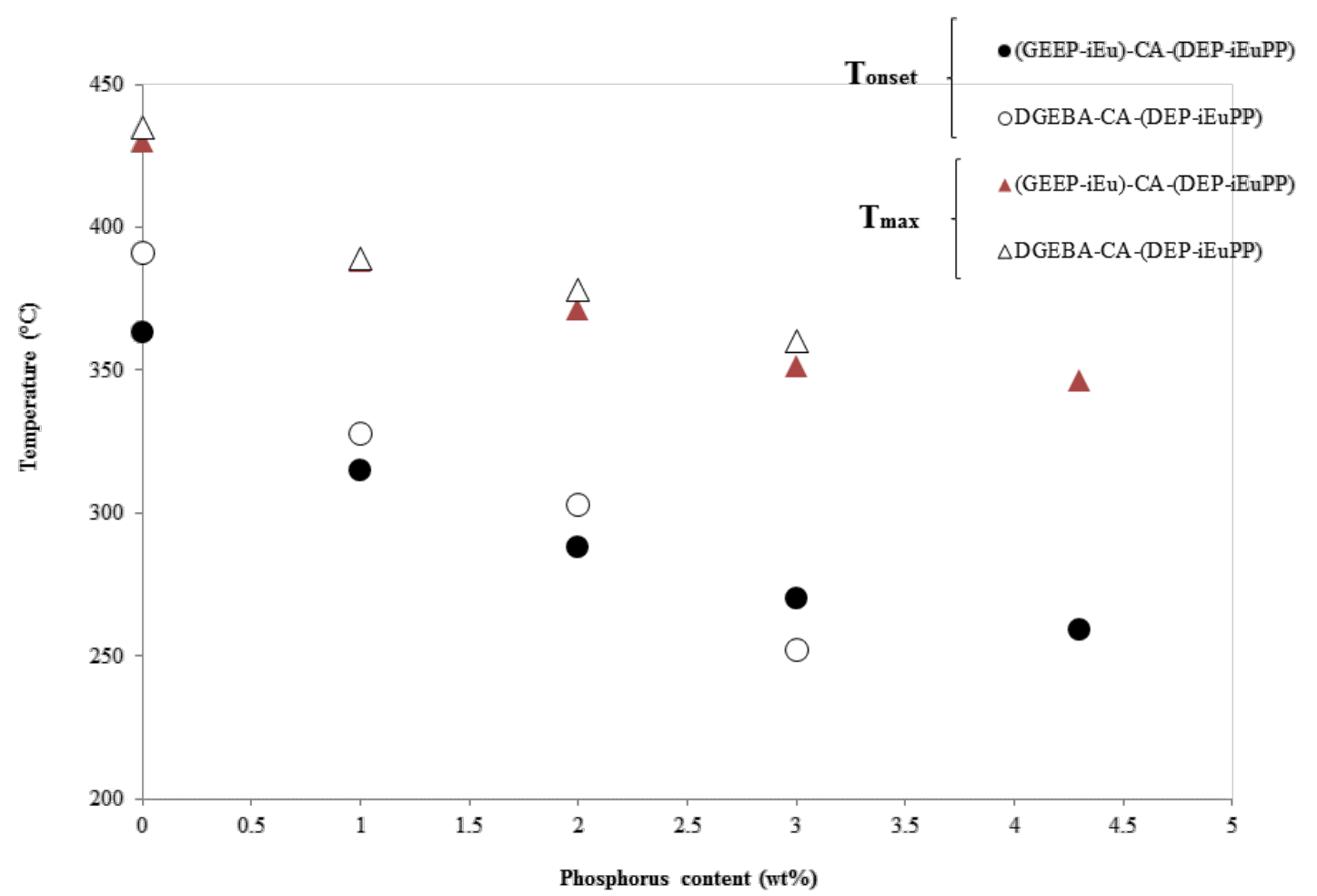

Figure 8. Onset temperatures $\left(\mathrm{T}_{5 \%}\right.$ ) and temperatures at peak of mass loss rate $\mathrm{T}_{\max }$ versus phosphorus content for DGEBA and GEEpiE series.

\section{Flame retardancy at bench-scale}


Some samples were characterized using cone calorimeter tests at an external heat flux of 35 $\mathrm{kWm}^{-2}$ (Figure 9 and table 4), which represent more realistic burning conditions than PCFC. All phosphorus-free resins exhibit a continuous increase of HRR after ignition up to a high peak of heat release rate $\left(1800-2100 \mathrm{~kW} \mathrm{~m}^{-2}\right)$ followed by a fast decrease due to fuel depletion. Residue content is limited and close to the values measured in TGA. The only difference concerns the time-to-ignition. DGEBA-CA appears to be more difficult to ignite. This thermoset was also the most thermally stable according to TGA.

The incorporation of phosphorus leads to a significant decrease of time-to-ignition. Such decrease is usual and can be assigned to the reduced stability of the resins as observed in TGA and PCFC. The ignition is followed by an increase of HRR up to a plateau during several dozens of seconds. Then HRR increases up to a pHRR which is twice as weak as the pHRR of the phosphorus-free counterpart. Char is significantly improved and in the same range as measured in TGA.

While char contents are similar in cone calorimeter and in TGA, it is possible to compare the effective heat of combustion (EHC) and the heat of complete combustion $(\Delta \mathrm{h})$. The ratio between both values corresponds to the combustion efficiency X. Phosphorus-free thermosets exhibit quite high combustion efficiency (0.79-0.95 depending on the thermoset). The incorporation of phosphorus leads to a significant decrease in combustion efficiency, which may be ascribed to a flame inhibition effect of phosphorus gases released in the flame.

Finally, total heat release is also significantly lower because a part of fuels is trapped into char and does not participate to combustion (charring promotion) but also because the combustion efficiency decreases.

Note that GEEpiE/CA with 2.0 and $3.0 \mathrm{w} \% \mathrm{P}$ exhibit very close flammability behavior. No further improvement is obtained when phosphorus content increases from 2.0 to $3.0 \mathrm{w} \%$. For 
DGEBA-based series, there is no more improvement of pHRR when phosphorus content increases from 2.0 to $3.0 \mathrm{w} \%$. But TTI decreases and char content increases significantly.

A proper comparison of flame retardancy with results from literature is quite difficult because of the major influence of the curing agent. For example, in a recent paper, several epoxy monomers based on eugenol and containing phosphate or phosphonate groups were cured with meta-xylylenediamine ${ }^{54}$. Performances at microscale were outstanding with very high char content and low pHRR and THR. Phosphorus contents were relatively higher (up to $5.8 \mathrm{wt} \%$ ) than in the present study but in one case it reaches $4.5 \mathrm{wt} \%$, which is similar to the value for DEpiEPP/CA. Nevertheless, the decrease in pHRR in cone calorimeter was similar: -55 to $60 \%$ versus $-60 \%$ for DGEBA/DEpiEPP /CA with $2 \mathrm{wt} \%$ of phosphorus. Menard et al. also found a decrease of $55 \%$ in pHRR in cone calorimeter for a network based on DGEBA, IPDA and an epoxy monomr containing phosphorus and sulfur called P2EP1SP (Diglycicyl thiophosphonate phloroglucinol - phosphorus content in epoxy resin was $3 \mathrm{wt} \%)^{64}$.

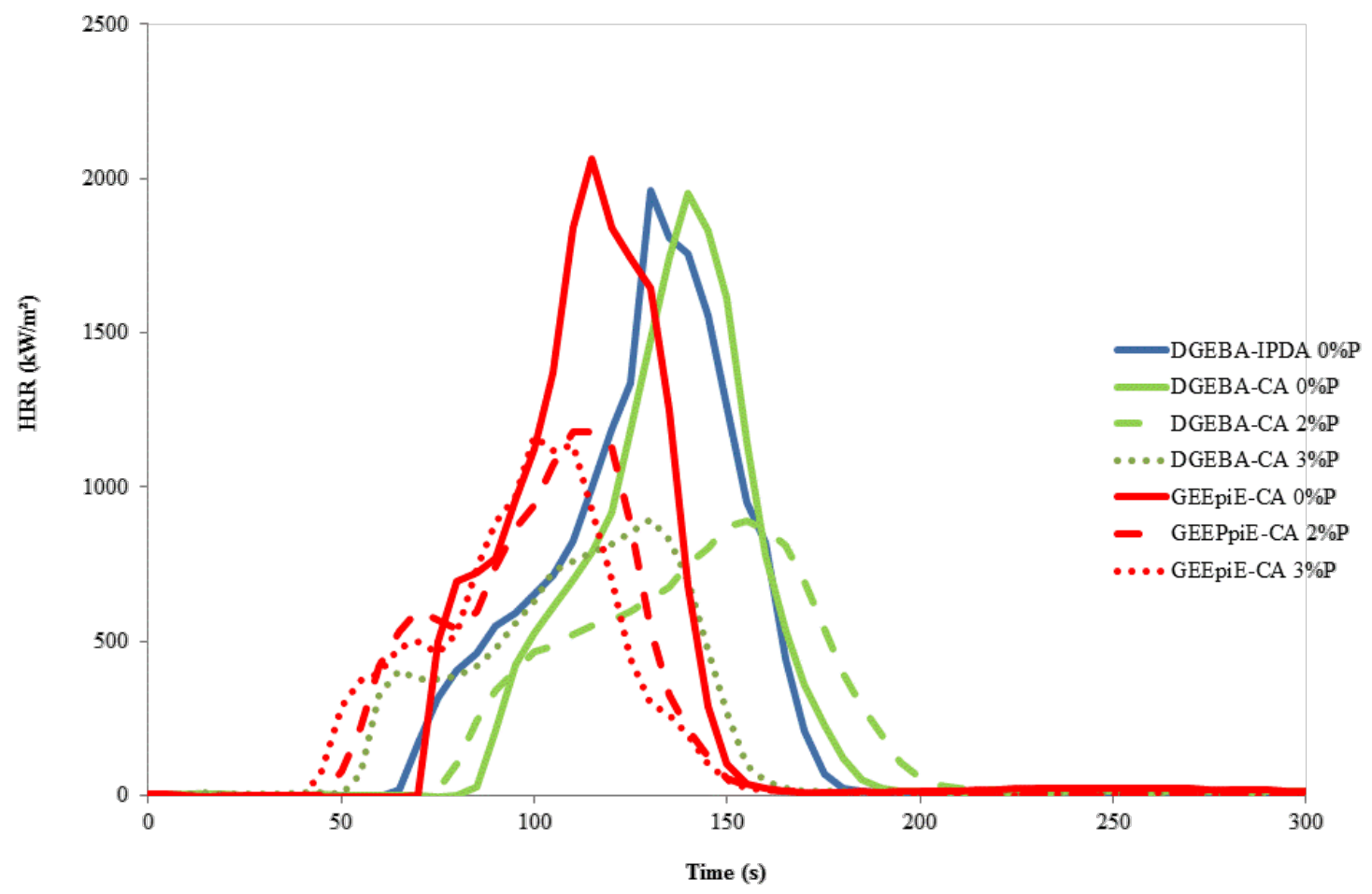

Figure 9. HRR curves obtained in cone calorimeter tests for several thermosets containing different phosphorus contents. 


\begin{tabular}{|c|c|c|c|c|c|c|c|c|}
\hline \multirow[t]{2}{*}{ Formulation } & $\%$ & TTI & $\mathrm{pHRR}$ & THR & THR & $\mathrm{EHC}$ & $\mathrm{X}$ & Residue \\
\hline & $\mathrm{P}$ & $S$ & $\mathrm{~kW} \cdot \mathrm{m}^{-2}$ & MJ.m $\mathrm{m}^{-2}$ & kJ.g ${ }^{-1}$ & kJ.g ${ }^{-1}$ & & $\mathrm{w} \%$ \\
\hline DGEBA/IPDA & 0.0 & 69 & 2145 & 99 & 22.7 & 24.5 & 0.79 & 6 \\
\hline DGEBA/CA & 0.0 & 87 & 1848 & 90 & 20.4 & 22.3 & 0.84 & 9 \\
\hline DGEBA/DEpiEPP /CA & 2.0 & 78 & 849 & 66 & 15.9 & 18 & 0.73 & 11.5 \\
\hline DGEBA/DEpiEPP /CA & 3.0 & 53 & 890 & 58 & 13.8 & 17 & 0.68 & 19 \\
\hline GEEpiE/CA & 0.0 & 71 & 2065 & 92 & 21.6 & 23.3 & 0.95 & 7.1 \\
\hline GEEpiE/DEpiEPP /CA & 2.0 & 48 & 1302 & 67 & 15.7 & 19.3 & 0.81 & 18.3 \\
\hline GEEpiE/DEpiEPP /CA & 3.0 & 43 & 1159 & 61 & 14.4 & 18.1 & 0.74 & 20.7 \\
\hline
\end{tabular}

Table 4 Data of the cone calorimeter analyses of all the prepared thermosets.

Pictures of some residues after cone calorimeter tests are shown in Figure 10. It is obvious than the incorporation of phosphorus groups leads to the formation of an expanded char. Such char may be able to prevent the heat and gas transfer between the flame and underlying material. Nevertheless, the shape of the HRR curves does not correspond to a thick charring behaviour and cannot prove the efficiency of the char as insulating layer. ${ }^{68}$

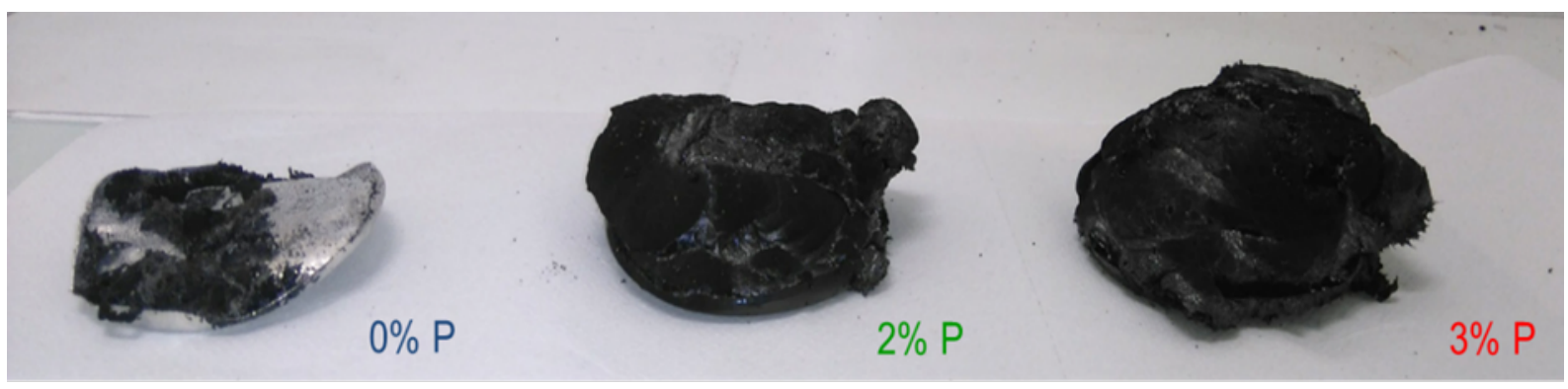

Figure 10. Pictures of the cone residues: GEEpiE/CA $(0.0 \% \mathrm{P}-2.0 \% \mathrm{P}$ and $3.0 \% \mathrm{P})$ thermosets obtained by cone calorimeter. 
The residual phosphorus content for the residues of the GEEpiE/CA series thermosets containing DEpiEPP was determined by ICP. Results are summarized in table 5. The phosphorus content is much higher in the char than in the initial corresponding resin, evidencing that a significant part of the phosphorus remains in the char and contributes to the formation of a thermally stable carbonaceous layer. For $3.0 \mathrm{w} \%$ of phosphorus initially in the resin, the phosphorus content in the char reaches $8.5 \mathrm{w} \%$. This value is close to that found by Menard et al. in the char obtained from DGEBA-IPDA-P2EP1SP after thermogravimetric analysis under nitrogen flow. ${ }^{60}$ Nevertheless, in the present work, only around $60 \%$ of phosphorus remains in the char versus $82 \%$ in the Menard's work. Note that the release of a significant amount of phosphorus in gas phase (i.e. around $40 \%$ ) is compatible with the flame inhibition effect suggested from combustion efficiency data.

\begin{tabular}{cccc}
\hline Notation & $\begin{array}{c}\text { Initial phosphorus } \\
\text { content in thermoset } \\
\end{array}$ & Average & Average residual \\
& $(\mathrm{w} \%)$ & in char $(\mathrm{w} \%)$ & $(\%)$ \\
GEEpiE/CA & 0.0 & 0 & 0 \\
\hline GEEpiE/DEpiEPP /CA & 2.0 & 6.78 & 62 \\
\hline GEEpiE/DEpiEPP /CA & 3.0 & 8.50 & 59
\end{tabular}

Table 5 Determination of the residual phosphorus content in the cone calorimeter residue of the GEEpiE/CA series thermosets containing DEpiEPP.

\section{Mechanical properties of the cured epoxy resins.}

The GEEpiE-CA-DEpiEPP and DGEBA-CA-DEpiEPP epoxy thermosets with a phosphorus weight content equal to $2 \%$ were also mechanically characterized using nanoindentaion and 3 point bending test. The nanoindentation properties obtained for these fully and partially biobased epoxy thermosets (Table 6) are in the high range of the target bracket and are fully 
suitable for structural applications. Noteworthy, they are in the same range as those previously reported for eugenol-based epoxy thermosets ${ }^{75}$. Interestingly, it can be observed that the highest properties are obtained for the fully bio-based epoxy with a relaxed modulus of 4.54 $\mathrm{GPa}$, an instantaneous modulus of $5.1 \mathrm{GPa}$ and a hardness of $278 \mathrm{MPa}$. The time-dependency is also slightly higher with a m value of approximately 0.032 .

\begin{tabular}{lcccc}
\hline Samples (2\%P) & $\mathrm{E}_{\mathrm{R}}(\mathrm{GPa})$ & $\mathrm{E}_{\mathrm{I}}(\mathrm{GPa})$ & $\mathrm{H}(\mathrm{MPa})$ & $\mathrm{m}(\varnothing)$ \\
\hline DGEBA/DEpiEPP/CA & $4.45 \pm 0.03$ & $4.8 \pm 0.03$ & $264 \pm 14$ & 0.020 \\
\hline GEEpiE / DEpiEPP / CA & $4.54 \pm 0.13$ & $5.1 \pm 0.05$ & $278 \pm 3$ & 0.032
\end{tabular}

Table 6. Properties measured with nanoindentation technique: average and standard deviation values of relaxed modulus $\left(\mathrm{E}_{\mathrm{R}}\right)$, instantaneous modulus $\left(\mathrm{E}_{\mathrm{I}}\right)$, hardness $(\mathrm{H})$ and strain rate sensitivity (m).

The 3-point bending test results are presented in table 7 and figure 11. For purposes of comparison, the mechanical characteristics of the commercial epoxy thermoset SR GreenPoxy $56 \AA$, according to Sicomin technical data sheet, are also given in table 7 . The values obtained for the DGEBA-CA-DEpiEPP epoxy are in line with the values generally reported in literature 12 and technical datasheet for the DGEBA-based systems ${ }^{69}$ and slightly higher than those of SR GreenPoxy 56®. The elastic modulus, maximum stress and strain at failure are equal to 4.3 GPa, $140 \mathrm{MPa}$ and 5\%, respectively. Concerning the rigidity, it can be observed that the same order of magnitude as the one obtained with nanoindentation is measured. The mean value for the GEEpiE-CA-DEpiEPP epoxy specimens is slightly lower $(6 \%)$ than for the DGEBA-CADEpiEPP epoxy ones. In any case, such an elastic modulus of approximately $4 \mathrm{GPa}$ is fully suitable for structural applications. A significant difference can be observed between the two epoxy systems for the maximum stress and strain at failure. The values measured for the GEEpiE-CA-DEpiEPP epoxy are $35 \%$ and $45 \%$ lower than for the DGEBA-CA-DEpiEPP epoxy polymer. Indeed, the stress-train curves (Fig. 11) show two different failure behavior. 
The DGEBA-CA-DEpiEPP epoxy polymer presents a ductile behavior with a yield point at approximately $85 \mathrm{MPa}$ and $2 \%$ of strain and then a strongly non-linear behavior attributed to plasticity. On the contrary, the GEEpiE-CA-DEpiEPP epoxy polymer exhibits an elasto-brittle behavior with a sudden failure after exceeding the yield point.

\begin{tabular}{lccc}
\hline & Modulus of elasticity & Stress at failure & Strain at failure \\
& $(\mathrm{GPa})$ & $(\mathrm{MPa})$ & $(\%)$ \\
\hline DGEBA/DEpiEPP/CA & $4.3 \pm 0.2$ & $140 \pm 4$ & $5.0 \pm 0.1$ \\
\hline GEEpiE/DEpiEPP/CA & $4.1 \pm 0.2$ & $90 \pm 1$ & $2.2 \pm 0.1$ \\
\hline SR GreenPoxy 56® & $3.0 \pm 0.2$ & $96 \pm 5$ & $8 \pm 2$ \\
\hline
\end{tabular}

Table 7. 3-point bending properties: average and standard deviation values of the elastic modulus, maximum stress and strain at failure.

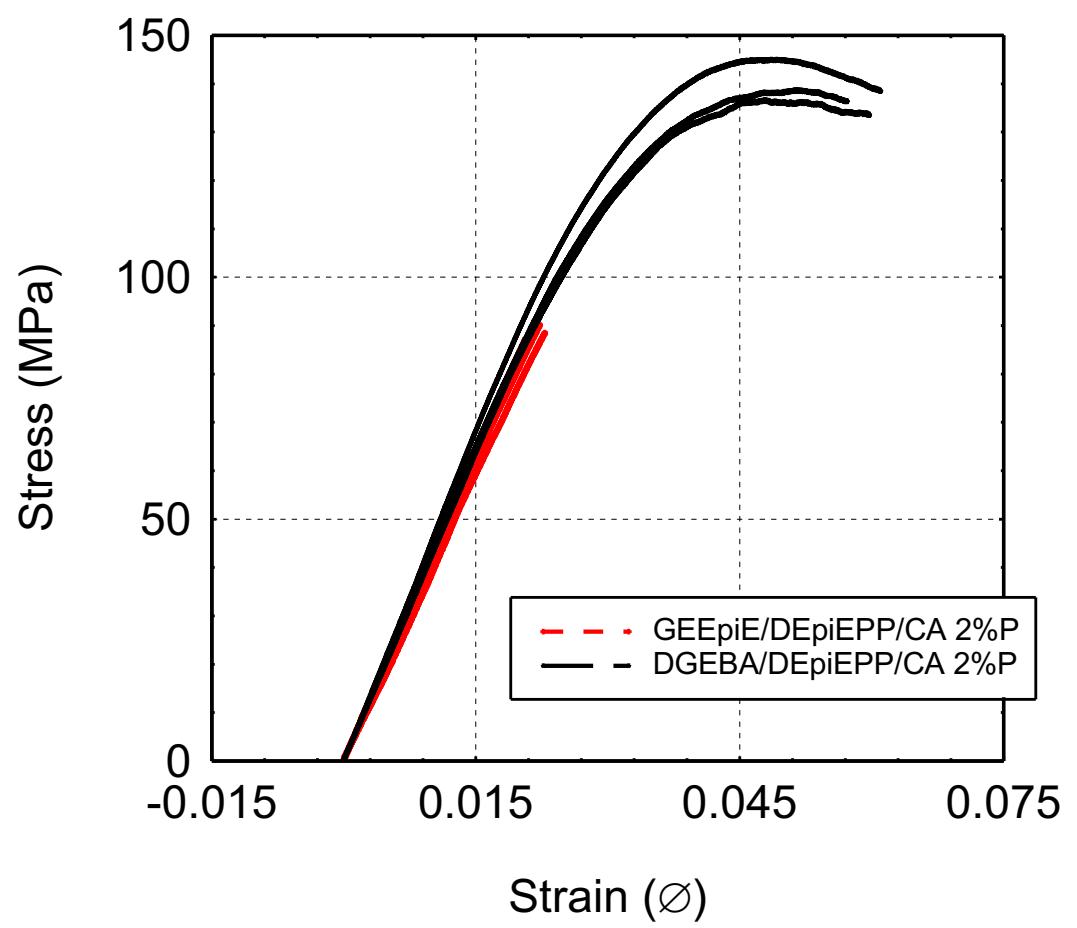

Figure 11. Bending stress/strain curves obtained for the GEEpiE-CA-DEpiEPP and DGEBACA-DEpiEPP epoxy thermosets with a phosphorus weight content equal to $2 \%$. 


\section{CONCLUSION}

A new bio-based epoxy phosphate FR derived from iso-eugenol was successfully synthesized and well characterized $\left({ }^{1} \mathrm{H},{ }^{13} \mathrm{C},{ }^{31} \mathrm{P}\right.$ NMR, FTIR, MS). This diepoxy-iso-eugenol phenylphosphate (DEpiEPP) was then copolymerized either with conventional diglycidylether of bisphenol A resin (DGEBA) or with a totally bio-based glycidylether epoxy iso-eugenol (GEEpiE) resin in the presence of the bio-based camphoric anhydride (CA) used as hardener. The cured resins $\left(2 \mathrm{~h}\right.$ at $\left.150^{\circ} \mathrm{C}\right)$ containing various contents of DEpiEPP were then mechanically and thermally characterized.

As the level of the DEpiEPP-FR monomer increases ( 0.0 to $4,3 \%$ wt $\mathrm{P})$, the $\mathrm{Tg}$ of the cured resin decreases from $155-162^{\circ} \mathrm{C}$ to $71^{\circ} \mathrm{C}$ when the final material only contains the DEpiEPPFR (4.3\% wt P). TGA, PCFC and cone calorimeter results reveal that DEpiEPP is a good flame retardant since it promotes a significant charring of both epoxy thermosets (DGEBA-DEpiEPPFR and GEEpiE-DEpiEPP-FR). Both formulations obtained with a ratio of $2 \%$ wt of $\mathrm{P}$ provide very promising green epoxy thermosets for developing high performance green composites (respectively $57 \%$ and $95 \%$ bio-based content). Indeed, the curing temperature of these epoxy thermosets remains compatible with the use of vegetable fibres and these epoxy matrices possess high $\mathrm{Tg}$ (respectively 129 and $105^{\circ} \mathrm{C}$ ), instantaneous elastic modulus of respectively 5.1 and 4.8 GPa, as well as high bending properties and demonstrate good flame-retardant properties due to char promotion.

Acknowledgments: "This project has received funding from the Bio Based Industries Joint Undertaking under the European Union's Horizon 2020 research and innovation program under grant agreement No 744349”; The authors are also grateful from the Centre National de la Recherche Scientifique (CNRS-France) and the University of Bourgogne Franche-Comté. 
The authors thanks Xavier Gabrion for his technical help. 
(1) Auvergne, R.; Caillol, S.; David, G.; Boutevin, B.; Pascault, J.-P. Biobased Thermosetting Epoxy: Present and Future. Chemical Reviews 2014, 114 (2), 1082-1115. https://doi.org/10.1021/cr3001274.

(2) Raquez, J.-M.; Deléglise, M.; Lacrampe, M.-F.; Krawczak, P. Thermosetting (Bio)Materials Derived from Renewable Resources: A Critical Review. Progress in Polymer Science 2010, 35 (4), 487-509. https://doi.org/10.1016/j.progpolymsci.2010.01.001.

(3) European Chemical Agency . Commitee for Risk Assesment RAC Proposing Hamonised Classification and Labelling at EU Level of Bisphenol A; Helsinki, Finland 2014. (4) Liu, X.; Zhang, J. High-Performance Biobased Epoxy Derived from Rosin. Polymer International 2010, n/a-n/a. https://doi.org/10.1002/pi.2781.

(5) Wang, X.; Zhou, S.; Guo, W.-W.; Wang, P.-L.; Xing, W.; Song, L.; Hu, Y. Renewable Cardanol-Based Phosphate as a Flame Retardant Toughening Agent for Epoxy Resins. ACS Sustainable Chem. Eng. 2017, 5 (4), 3409-3416. https://doi.org/10.1021/acssuschemeng.7b00062.

(6) François, C.; Pourchet, S.; Boni, G.; Rautiainen, S.; Samec, J.; Fournier, L.; Robert, C.; Thomas, C. M.; Fontaine, S.; Gaillard, Y.; et al. Design and Synthesis of Biobased Epoxy Thermosets from Biorenewable Resources. Comptes Rendus Chimie 2017, 20 (11-12), 10061016. https://doi.org/10.1016/j.crci.2017.10.005.

(7) François, C.; Pourchet, S.; Boni, G.; Fontaine, S.; Gaillard, Y.; Placet, V.; Galkin, M. V.; Orebom, A.; Samec, J.; Plasseraud, L. Diglycidylether of Iso-Eugenol: A Suitable LigninDerived Synthon for Epoxy Thermoset Applications. RSC Advances 2016, 6 (73), 6873268738. https://doi.org/10.1039/C6RA15200G.

(8) Qin, J.; Liu, H.; Zhang, P.; Wolcott, M.; Zhang, J. Use of Eugenol and Rosin as Feedstocks for Biobased Epoxy Resins and Study of Curing and Performance Properties: Use of Eugenol and Rosin as Feedstocks. Polymer International 2014, 63 (4), 760-765. https://doi.org/10.1002/pi.4588.

(9) Jiang, H.; Sun, L.; Zhang, Y.; Liu, Q.; Ru, C.; Zhang, W.; Zhao, C. Novel Biobased Epoxy Resin Thermosets Derived from Eugenol and Vanillin. Polymer Degradation and Stability 2019, 160, 45-52. https://doi.org/10.1016/j.polymdegradstab.2018.12.007.

(10) Wan, J.; Zhao, J.; Gan, B.; Li, C.; Molina-Aldareguia, J.; Zhao, Y.; Pan, Y.-T.; Wang, D.-Y. Ultrastiff Biobased Epoxy Resin with High Tg and Low Permittivity: From Synthesis to Properties. ACS Sustainable Chem. Eng. 2016, 4 (5), 2869-2880. https://doi.org/10.1021/acssuschemeng.6b00479.

(11) Faye, I.; Decostanzi, M.; Ecochard, Y.; Caillol, S. Eugenol Bio-Based Epoxy Thermosets: From Cloves to Applied Materials. Green Chem. 2017, 19 (21), 5236-5242. https://doi.org/10.1039/C7GC02322G.

(12) Miao, J.-T.; Yuan, L.; Guan, Q.; Liang, G.; Gu, A. Biobased Heat Resistant Epoxy Resin with Extremely High Biomass Content from 2,5-Furandicarboxylic Acid and Eugenol. ACS Sustainable Chemistry \& Engineering 2017, 5 (8), 7003-7011. https://doi.org/10.1021/acssuschemeng.7b01222.

(13) Wang, X.-L.; Chen, L.; Wu, J.-N.; Fu, T.; Wang, Y.-Z. Flame-Retardant PressureSensitive Adhesives Derived from Epoxidized Soybean Oil and Phosphorus-Containing Dicarboxylic Acids. ACS Sustainable Chemistry \& Engineering 2017, 5 (4), 3353-3361. https://doi.org/10.1021/acssuschemeng.6b03201.

(14) Zhao, S.; Huang, X.; Whelton, A. J.; Abu-Omar, M. M. Formaldehyde-Free Method for Incorporating Lignin into Epoxy Thermosets. ACS Sustainable Chem. Eng. 2018, 6 (8), 10628-10636. https://doi.org/10.1021/acssuschemeng.8b01962.

(15) van de Pas, D. J.; Torr, K. M. Biobased Epoxy Resins from Deconstructed Native Softwood Lignin. Biomacromolecules 2017, 18 (8), 2640-2648. https://doi.org/10.1021/acs.biomac.7b00767. 
(16) Jung, J. Y.; Park, C.-H.; Lee, E. Y. Epoxidation of Methanol-Soluble Kraft Lignin for Lignin-Derived Epoxy Resin and Its Usage in the Preparation of Biopolyester. Journal of Wood Chemistry and Technology 2017, 37 (6), 433-442. https://doi.org/10.1080/02773813.2017.1310901.

(17) Savonnet, E.; Grau, E.; Grelier, S.; Defoort, B.; Cramail, H. Divanillin-Based Epoxy Precursors as DGEBA Substitutes for Biobased Epoxy Thermosets. ACS Sustainable Chem. Eng. 2018, 6 (8), 11008-11017. https://doi.org/10.1021/acssuschemeng.8b02419.

(18) Mora, A.-S.; Tayouo, R.; Boutevin, B.; David, G.; Caillol, S. Vanillin-Derived Amines for Bio-Based Thermosets. Green Chemistry 2018, 20 (17), 4075-4084. https://doi.org/10.1039/C8GC02006J.

(19) Shibata, M.; Ohkita, T. Fully Biobased Epoxy Resin Systems Composed of a VanillinDerived Epoxy Resin and Renewable Phenolic Hardeners. European Polymer Journal 2017, 92, 165-173. https://doi.org/10.1016/j.eurpolymj.2017.05.007.

(20) Couture, G.; Granado, L.; Fanget, F.; Boutevin, B.; Caillol, S. Limonene-Based Epoxy: Anhydride Thermoset Reaction Study. Molecules 2018, 23 (11), 2739.

https://doi.org/10.3390/molecules23112739.

(21) Dai, J.; Peng, Y.; Teng, N.; Liu, Y.; Liu, C.; Shen, X.; Mahmud, S.; Zhu, J.; Liu, X. High-Performing and Fire-Resistant Biobased Epoxy Resin from Renewable Sources. ACS Sustainable Chem. Eng. 2018, 6 (6), 7589-7599. https://doi.org/10.1021/acssuschemeng.8b00439.

(22) Llevot, A.; Grau, E.; Carlotti, S.; Grelier, S.; Cramail, H. From Lignin-Derived Aromatic Compounds to Novel Biobased Polymers. Macromolecular Rapid Communications 2016, 37 (1), 9-28. https://doi.org/10.1002/marc.201500474.

(23) Zhao, S.; Abu-Omar, M. M. Renewable Epoxy Networks Derived from Lignin-Based Monomers: Effect of Cross-Linking Density. ACS Sustainable Chem. Eng. 2016, 4 (11), 6082-6089. https://doi.org/10.1021/acssuschemeng.6b01446.

(24) Gioia, C.; Lo Re, G.; Lawoko, M.; Berglund, L. Tunable Thermosetting Epoxies Based on Fractionated and Well-Characterized Lignins. J. Am. Chem. Soc. 2018, 140 (11), 4054-4061. https://doi.org/10.1021/jacs.7b13620.

(25) Jiang, Y.; Ding, D.; Zhao, S.; Zhu, H.; Kenttämaa, H. I.; Abu-Omar, M. M. Renewable Thermoset Polymers Based on Lignin and Carbohydrate Derived Monomers. Green Chemistry 2018, 20 (5), 1131-1138. https://doi.org/10.1039/C7GC03552G.

(26) Zhao, S.; Abu-Omar, M. M. Synthesis of Renewable Thermoset Polymers through Successive Lignin Modification Using Lignin-Derived Phenols. ACS Sustainable Chem. Eng. 2017, 5 (6), 5059-5066. https://doi.org/10.1021/acssuschemeng. $7 b 00440$.

(27) Fache, M.; Boutevin, B.; Caillol, S. Epoxy Thermosets from Model Mixtures of the Lignin-to-Vanillin Process. Green Chemistry 2016, 18 (3), 712-725.

https://doi.org/10.1039/C5GC01070E.

(28) Nicastro, K. H.; Kloxin, C. J.; Epps, T. H. Potential Lignin-Derived Alternatives to Bisphenol A in Diamine-Hardened Epoxy Resins. ACS Sustainable Chem. Eng. 2018, 6 (11), 14812-14819. https://doi.org/10.1021/acssuschemeng.8b03340.

(29) Ragauskas, A. J.; Beckham, G. T.; Biddy, M. J.; Chandra, R.; Chen, F.; Davis, M. F.; Davison, B. H.; Dixon, R. A.; Gilna, P.; Keller, M.; et al. Lignin Valorization: Improving Lignin Processing in the Biorefinery. Science 2014, 344 (6185), 1246843-1246843. https://doi.org/10.1126/science.1246843.

(30) Sun, Z.; Fridrich, B.; de Santi, A.; Elangovan, S.; Barta, K. Bright Side of Lignin Depolymerization: Toward New Platform Chemicals. Chemical Reviews 2018, 118 (2), 614 678. https://doi.org/10.1021/acs.chemrev.7b00588.

(31) Ma, S.; Liu, X.; Jiang, Y.; Tang, Z.; Zhang, C.; Zhu, J. Bio-Based Epoxy Resin from Itaconic Acid and Its Thermosets Cured with Anhydride and Comonomers. Green Chem. 
2013, 15 (1), 245-254. https://doi.org/10.1039/C2GC36715G.

(32) Yang, G.; Rohde, B. J.; Tesefay, H.; Robertson, M. L. Biorenewable Epoxy Resins Derived from Plant-Based Phenolic Acids. ACS Sustainable Chemistry \& Engineering 2016, 4 (12), 6524-6533. https://doi.org/10.1021/acssuschemeng.6b01343.

(33) Mouritz, A. P.; Mathys, Z.; Gibson, A. G. Heat Release of Polymer Composites in Fire. Composites Part A: Applied Science and Manufacturing 2006, 37 (7), 1040-1054. https://doi.org/10.1016/j.compositesa.2005.01.030.

(34) Schartel, B. Phosphorus-Based Flame Retardancy Mechanisms - Old Hat or a Starting Point for Future Development? Materials 2010, 3 (10), 4710-4745. https://doi.org/10.3390/ma3104710.

(35) Hergenrother, P. M.; Thompson, C. M.; Smith, J. G.; Connell, J. W.; Hinkley, J. A.; Lyon, R. E.; Moulton, R. Flame Retardant Aircraft Epoxy Resins Containing Phosphorus. Polymer 2005, 46 (14), 5012-5024. https://doi.org/10.1016/j.polymer.2005.04.025.

(36) Braun, U.; Balabanovich, A. I.; Schartel, B.; Knoll, U.; Artner, J.; Ciesielski, M.; Döring, M.; Perez, R.; Sandler, J. K. W.; Altstädt, V.; et al. Influence of the Oxidation State of Phosphorus on the Decomposition and Fire Behaviour of Flame-Retarded Epoxy Resin Composites. Polymer 2006, 47 (26), 8495-8508.

https://doi.org/10.1016/j.polymer.2006.10.022.

(37) Salmeia, K. A.; Gaan, S. An Overview of Some Recent Advances in DOPODerivatives: Chemistry and Flame Retardant Applications. Polymer Degradation and Stability 2015, 113, 119-134. https://doi.org/10.1016/j.polymdegradstab.2014.12.014. (38) Salmeia, K. A.; Gooneie, A.; Simonetti, P.; Nazir, R.; Kaiser, J.-P.; Rippl, A.; Hirsch, C.; Lehner, S.; Rupper, P.; Hufenus, R.; et al. Comprehensive Study on Flame Retardant Polyesters from Phosphorus Additives. Polymer Degradation and Stability 2018, 155, 22-34. https://doi.org/10.1016/j.polymdegradstab.2018.07.006.

(39) Howell, B. A.; Sun, W. Biobased Flame Retardants from Tartaric Acid and Derivatives. Polymer Degradation and Stability 2018, 157, 199-211. https://doi.org/10.1016/j.polymdegradstab.2018.10.006.

(40) Ménard, R.; Negrell-Guirao, C.; Ferry, L.; Sonnier, R.; David, G. Synthesis of Biobased Phosphate Flame Retardants. Pure and Applied Chemistry 2014, 86 (11), 16371650. https://doi.org/10.1515/pac-2014-0703.

(41) Schäfer, A.; Seibold, S.; Walter, O.; Döring, M. Novel High Tg Flame Retardancy Approach for Epoxy Resins. Polymer Degradation and Stability 2008, 93 (2), 557-560. https://doi.org/10.1016/j.polymdegradstab.2007.11.016.

(42) Hou, M.; Liu, W.; Su, Q.; Liu, Y. Studies on the Thermal Properties and Flame Retardancy of Epoxy Resins Modified with Polysiloxane Containing Organophosphorus and Epoxide Groups. Polymer Journal 2007, 39 (7), 696-702.

https://doi.org/10.1295/polymj.PJ2006111.

(43) Huo, S.; Wang, J.; Yang, S.; Zhang, B.; Chen, X.; Wu, Q.; Yang, L. Synthesis of a Novel Reactive Flame Retardant Containing Phosphaphenanthrene and Piperidine Groups and Its Application in Epoxy Resin. Polymer Degradation and Stability 2017, 146, 250-259. https://doi.org/10.1016/j.polymdegradstab.2017.10.015.

(44) Huo, S.; Wang, J.; Yang, S.; Li, C.; Wang, X.; Cai, H. Synthesis of a DOPOContaining Imidazole Curing Agent and Its Application in Reactive Flame Retarded Epoxy Resin. Polymer Degradation and Stability 2019, 159, 79-89.

https://doi.org/10.1016/j.polymdegradstab.2018.11.021.

(45) Huo, S.; Liu, Z.; Li, C.; Wang, X.; Cai, H.; Wang, J. Synthesis of a Phosphaphenanthrene/Benzimidazole-Based Curing Agent and Its Application in FlameRetardant Epoxy Resin. Polymer Degradation and Stability 2019, 163, 100-109. https://doi.org/10.1016/j.polymdegradstab.2019.03.003. 
(46) Shi, Y.-Q.; Fu, T.; Xu, Y.-J.; Li, D.-F.; Wang, X.-L.; Wang, Y.-Z. Novel PhosphorusContaining Halogen-Free Ionic Liquid toward Fire Safety Epoxy Resin with Well-Balanced Comprehensive Performance. Chemical Engineering Journal 2018, 354, 208-219. https://doi.org/10.1016/j.cej.2018.08.023.

(47) Sonnier, R.; Dumazert, L.; Livi, S.; Nguyen, T. K. L.; Duchet-Rumeau, J.; Vahabi, H.; Laheurte, P. Flame Retardancy of Phosphorus-Containing Ionic Liquid Based Epoxy Networks. Polymer Degradation and Stability 2016, 134, 186-193. https://doi.org/10.1016/j.polymdegradstab.2016.10.009.

(48) Ma, S.; Liu, X.; Jiang, Y.; Fan, L.; Feng, J.; Zhu, J. Synthesis and Properties of Phosphorus-Containing Bio-Based Epoxy Resin from Itaconic Acid. Science China Chemistry 2014, 57 (3), 379-388. https://doi.org/10.1007/s1 1426-013-5025-3.

(49) Yang, X.; Wang, C.; Xia, J.; Mao, W.; Li, S. Study on Synthesis of Novel PhosphorusContaining Flame Retardant Epoxy Curing Agents from Renewable Resources and the Comprehensive Properties of Their Combined Cured Products. Progress in Organic Coatings 2017, 110, 195-203. https://doi.org/10.1016/j.porgcoat.2017.01.012.

(50) Miao, J.-T.; Yuan, L.; Guan, Q.; Liang, G.; Gu, A. Biobased Epoxy Resin Derived from Eugenol with Excellent Integrated Performance and High Renewable Carbon Content: Biobased Epoxy Resin Derived from Eugenol. Polym. Int. 2018, 67 (9), 1194-1202. https://doi.org/10.1002/pi.5621.

(51) Wang, S.; Ma, S.; Xu, C.; Liu, Y.; Dai, J.; Wang, Z.; Liu, X.; Chen, J.; Shen, X.; Wei, J.; et al. Vanillin-Derived High-Performance Flame Retardant Epoxy Resins: Facile Synthesis and Properties. Macromolecules 2017, 50 (5), 1892-1901.

https://doi.org/10.1021/acs.macromol.7b00097.

(52) Wang, S.; Ma, S.; Li, Q.; Yuan, W.; Wang, B.; Zhu, J. Robust, Fire-Safe, MonomerRecovery, Highly Malleable Thermosets from Renewable Bioresources. Macromolecules 2018, 51 (20), 8001-8012. https://doi.org/10.1021/acs.macromol.8b01601.

(53) Xu, X.; Wang, S.; Ma, S.; Yuan, W.; Li, Q.; Feng, J.; Zhu, J. Vanillin-Derived Phosphorus-Containing Compounds and Ammonium Polyphosphate as Green Fire-Resistant Systems for Epoxy Resins with Balanced Properties. Polym Adv Technol 2019, 30 (2), 264 278. https://doi.org/10.1002/pat.4461.

(54) Ecochard; Decostanzi; Negrell; Sonnier; Caillol. Cardanol and Eugenol Based Flame Retardant Epoxy Monomers for Thermostable Networks. Molecules 2019, 24 (9), 1818. https://doi.org/10.3390/molecules24091818.

(55) Wan, J.; Gan, B.; Li, C.; Molina-Aldareguia, J.; Li, Z.; Wang, X.; Wang, D.-Y. A Novel Biobased Epoxy Resin with High Mechanical Stiffness and Low Flammability: Synthesis, Characterization and Properties. Journal of Materials Chemistry A 2015, 3 (43), 21907-21921. https://doi.org/10.1039/C5TA02939B.

(56) Li, C.; Fan, H.; Aziz, T.; Bittencourt, C.; Wu, L.; Wang, D.-Y.; Dubois, P. Biobased Epoxy Resin with Low Electrical Permissivity and Flame Retardancy: From Environmental Friendly High-Throughput Synthesis to Properties. ACS Sustainable Chemistry \& Engineering 2018, 6 (7), 8856-8867. https://doi.org/10.1021/acssuschemeng.8b01212.

(57) Robert, C.; de Montigny, F.; Thomas, C. M. Facile and Efficient Synthesis of Cyclic Anhydrides from Dicarboxylic Acids. ACS Catal. 2014, 4 (10), 3586-3589.

https://doi.org/10.1021/cs501237p.

(58) Laoutid, F.; Bonnaud, L.; Alexandre, M.; Lopez-Cuesta, J.-M.; Dubois, Ph. New Prospects in Flame Retardant Polymer Materials: From Fundamentals to Nanocomposites. Materials Science and Engineering: R: Reports 2009, 63 (3), 100-125. https://doi.org/10.1016/j.mser.2008.09.002.

(59) Huggett, C. Estimation of Rate of Heat Release by Means of Oxygen Consumption Measurements. Fire and Materials 1980, 4 (2), 61-65. 
https://doi.org/10.1002/fam.810040202.

(60) Galkin, M. V.; Samec, J. S. M. Selective Route to 2-Propenyl Aryls Directly from Wood by a Tandem Organosolv and Palladium-Catalysed Transfer Hydrogenolysis.

ChemSusChem 2014, 7 (8), 2154-2158. https://doi.org/10.1002/cssc.201402017.

(61) Lafont, D.; D’Attoma, J.; Gomez, R.; Goekjian, P. G. Epoxidation of Glycals with Oxone-Acetone-Tetrabutylammonium Hydrogen Sulfate: A Convenient Access to Simple $\beta$ d-Glycosides and to $\alpha$-d-Mannosamine and d-Talosamine Donors. Tetrahedron: Asymmetry 2011, 22 (11), 1197-1204. https://doi.org/10.1016/j.tetasy.2011.06.027.

(62) González, L.; Ferrando, F.; Ramis, X.; Salla, J. M.; Mantecón, A.; Serra, A. Characterization of New Reworkable Thermosetting Coatings Obtained by Cationic and Anionic Curing of DGEBA and Some Meldrum Acid Derivatives. Progress in Organic Coatings 2009, 65 (2), 175-181. https://doi.org/10.1016/j.porgcoat.2008.10.007.

(63) Bertoncini, M.; Hoepfner, J.; Pezzin, S. A Novel Route for the Amidation of Carbon Nanotubes and Their Use as Rein-Forcement in Epoxy Matrix Composites. Current Organic Chemistry 2013, 17 (17), 1838-1843. https://doi.org/10.2174/13852728113179990085.

(64) Ménard, R.; Negrell, C.; Ferry, L.; Sonnier, R.; David, G. Synthesis of Biobased Phosphorus-Containing Flame Retardants for Epoxy Thermosets Comparison of Additive and Reactive Approaches. Polymer Degradation and Stability 2015, 120, 300-312. https://doi.org/10.1016/j.polymdegradstab.2015.07.015.

(65) Ménard, R.; Negrell, C.; Fache, M.; Ferry, L.; Sonnier, R.; David, G. From a BioBased Phosphorus-Containing Epoxy Monomer to Fully Bio-Based Flame-Retardant Thermosets. RSC Advances 2015, 5 (87), 70856-70867. https://doi.org/10.1039/C5RA12859E.

(66) Walters, R. N.; Safronava, N.; Lyon, R. E. A Microscale Combustion Calorimeter Study of Gas Phase Combustion of Polymers. Combustion and Flame 2015, 162 (3), 855863. https://doi.org/10.1016/j.combustflame.2014.08.008.

(67) Sonnier, R.; Viretto, A.; Otazaghine, B.; Dumazert, L.; Evstratov, A.; Roux, J.-C.; Heruijing, C.; Presti, C.; Alauzun, J. G.; Mutin, P. H.; et al. Studying the Thermo-Oxidative Stability of Chars Using Pyrolysis-Combustion Flow Calorimetry. Polymer Degradation and Stability 2016, 134, 340-348. https://doi.org/10.1016/j.polymdegradstab.2016.11.007.

(68) Schartel, B.; Hull, T. R. Development of Fire-Retarded Materials-Interpretation of Cone Calorimeter Data. Fire Mater. 2007, 31 (5), 327-354. https://doi.org/10.1002/fam.949. (69) Jin FL; Li X; Park SJ. Synthesis and Application of Epoxy Resins: A Review. J. Ind. Eng. Chem. 2015, 29, 1-11. https://doi.org/10.1016/j.jiec.2015.03.026. 


\section{For Table of Contents Use Only}

Scheme 1. Molecular representations of reagents used. Epoxy monomers: diglycidylether of bisphenol A (DGEBA), glycidylether of phenoxy iso-eugenol (GEEpiE). Flame retardants: diepoxyiso-eugenolphenylphosphate (DEpiEPP). Curing agents: isophorone diamine (IPDA), camphoric anhydride (CA), phthalic anhydride (PA) and diphenic anhydride (DPA). Catalyst: 1,2-dimethylimidazole (DMID).

Scheme 2. Description of the diepoxy monomers synthesis.

Figure 1. ${ }^{31} \mathrm{P}$ NMR spectra of PPDC (left) and DEpiEPP (right)

Figure 2. ${ }^{1} \mathrm{H}$ NMR spectra of: (a) DiEPP and (b) DEpiEPP

Figure 3. ${ }^{13} \mathrm{C}$ NMR spectra of DEpiEPP.

Figure 4. DSC curves of dynamic curing reaction (above) DGEBA/CA (below) GEEpiE/CA series thermosets with varying DEpiEPP contents (0.0 to $4.3 \% \mathrm{P})$.

Figure 5. Determination of the glass transition by DSC (above) DGEBA/CA and (below) GEEpiE/CA thermoset series at different phosphorus content of DEpiEPP.

Figure 6. Thermograms of (above) DGEBA/CA and (below) GEEpiE/CA thermoset series at different phosphorus contents obtained by TGA at $20{ }^{\circ} \mathrm{C} \mathrm{min}^{-1}$ under nitrogen atmosphere.

Figure 7. HRR curves of (left) DGEBA/IPDA and DGEBA/CA and (right) GEEpiE/CA thermoset series at different phosphorus contents obtained by PCFC in standard conditions.

Figure 8. Onset temperatures $\left(\mathrm{T}_{5 \%}\right.$ ) and temperatures at peak of mass loss rate $\mathrm{T}_{\max }$ versus phosphorus content for DGEBA and GEEpiE series.

Figure 9. HRR curves obtained in cone calorimeter tests for several thermosets containing different phosphorus contents. 
Figure 10. Pictures of the cone residues: GEEpiE/CA $(0.0 \% \mathrm{P}-2.0 \% \mathrm{P}$ and $3.0 \% \mathrm{P})$ thermosets obtained by cone calorimeter.

Figure 11. Bending stress/strain curves obtained for the GEEpiE-CA-DEpiEPP and DGEBACA-DEpiEPP epoxy thermosets with a phosphorus weight content equal to $2 \%$.

Table 1 Weight compositions data of the thermosets.

Table 2 DSC data of the thermosets.

Table 3 Data of the TGA and PCFC analyses of all the prepared thermosets.

Table 4 Data of the cone calorimeter analyses of all the prepared thermosets.

Table 5 Determination of the residual phosphorus content in the cone calorimeter residue of the GEEpiE/CA series thermosets containing DEpiEPP.

Table 6 Properties measured with nanoindentation technique: average and standard deviation values of relaxed modulus $\left(E_{R}\right)$, instantaneous modulus $\left(E_{I}\right)$, hardness $(H)$ and strain rate sensitivity (m).

Table 7 3-point bending properties: average and standard deviation values of the elastic modulus, maximum stress and strain at failure.

\section{Graphical abstract:}

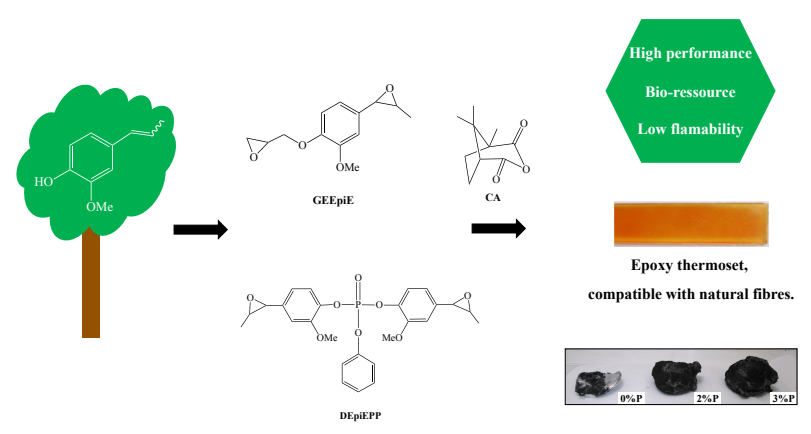




\section{Synopsis ( 20 words)}

High performance and fire-resistant green epoxy thermosets are prepared using iso-eugenol, a bio-ressource easily available from lignin. 